\title{
Effects of olive mill wastewater disposal on soil: Interaction mechanisms during different seasons
}

\author{
Nisreen Tamimi ${ }^{1}$, Dörte Diehl ${ }^{1}$, Mohand Njoum ${ }^{2}$, Amer Marei $^{2}$, Gabriele E. Schaumann ${ }^{1 *}$ \\ ${ }^{1}$ Universität Koblenz-Landau, Institute for Environmental Sciences, Group of Environmental and Soil Chemistry, Fortstr. 7, 76829 Lan- \\ dau, Germany. \\ ${ }^{2}$ Al-Quds University, Faculty of Science, The Earth and Environmental Science Department, Jerusalem, P.O. Box 2000, Palestinian Terri- \\ tories. \\ *Corresponding author. E-mail: schaumann@uni-landau.de
}

\begin{abstract}
Environmental conditions play a major role for effects of olive mill wastewater (OMW) application to soil. Choosing a different season for OMW application than the commonly practiced winter, may help avoid negative effects. However, understanding of the OMW-soil interaction during different seasons is still incomplete due to the lack of comparative data. In this study, an 18 months field experiment was carried out in an olive orchard in West Bank. Degree and persistence of soil salinization, acidification, accumulation of phenolic compounds and soil water repellency were investigated as a function of soil depth and time elapsed after OMW application, which was performed either in spring, summer (with and without irrigation) or winter. The persistence of negative effects increased with duration of the hot and dry period following the application due to accumulation and polymerization of OMW. On the other hand, leaching of OMW components to groundwater is favored during the rainy season and by formation of preferential flow paths before the rain season starts. The risks of groundwater contamination and persistent negative effects decrease with increasing time under conditions favoring biological activity. Therefore, OMW application in spring if improved by a careful irrigation is considered as the most suitable under semiarid conditions for clay loam soils.
\end{abstract}

Keywords: Olive mill wastewater; Soil water repellency; Acidification; Salinity; Soluble phenolic compounds; Leaching.

\section{INTRODUCTION}

Olive mill wastewater (OMW) treatment and management pose major concerns for many Mediterranean countries due to the specific characteristics of OMW such as its high biological and chemical oxygen demand (Hanafi et al., 2013), high concentration of oils and greases (Amaral et al., 2008), high salinity (Roig et al., 2006) and content of phenolic compounds (De Marco et al., 2007; Hanifi and El Hadrami, 2008). Furthermore, decentralized olive oil production makes the treatment of OMW in municipal sewage systems difficult and unfeasible. Consequently, a common practice for OMW disposal has been its discharge into the soil, with varying level of control in order to limit its potential negative effects on the soil and groundwater.

Several Mediterranean countries enforce upper limits for OMW discharge into the soil (Buchmann et al., 2015) in order to avoid negative environmental impact associated with OMW disposal, but many do not control it. The West Bank of the Palestinian Territory is one case of the latter (Peikert et al., 2015) and is the focus of the current study. According to the Palestinian Central Bureau of Statistics (2013), at least, 52.5\% of the cultivated land in the West Bank, estimated at $881.9 \mathrm{~km}^{2}$, is planted by olive trees. From 2010 to 2013, 275 olive mills, operated using the "three-phase technology", produced 67,459 tons of olive oil, and about $1.0-1.2 \mathrm{~m}^{3}$ of OMW for each ton of olive oil (Hanifi and El Hadrami, 2009; Saadi et al., 2007a); the resulting OMW was discharged in an uncontrolled manner into open fields and valleys.

The use of OMW for soil improvement has been proposed by several authors and comprehensively reviewed by Barbera et al. (2013). The high content of OMW organic matter and other nutrients, especially potassium (Roig et al., 2006), makes it valuable as a soil supplement (Mekki et al., 2006). However, the organic fraction of OMW contains sugars, polyphenols, tannins and lipids (Mulinacci et al., 2001) and is hardly biologically degradable due to the toxic effects of polyphenols (Saviozzi et al., 1991; Sobhi et al., 2008). It contains $0.5-$ $24 \mathrm{~g} \mathrm{~L}^{-1}$ of phenolic compounds (Niaounakis and Halvadakis, 2006), and phytotoxic effects have been observed when it was directly used as an organic fertilizer (Ben Sassi et al., 2006). Many studies showed contradictory results about permanence and toxicity of phenolic compounds in soil which can be attributed to a) the different amounts of toxic organic compounds present in OMW (Piotrowska et al., 2006), b) different soil temperature and moisture during and after OMW application which can affect the biological decomposition process of organic matter constitutes (Steinmetz et al., 2015), or reduce the inhibition effect by dilution and leaching of toxic compound under the influence of irrigation (Kurtz et al., 2015), and c) the general status of soil (Saadi et al., 2007a). However, Buchmann et al. (2015) showed in an incubation study of soil treated by OMW under spring conditions, that its phytotoxicity was clearly attributed to phenolic substances. Other studies showed a rapid decrease in phenolic compounds (Di Serio et al., 2008) and degradation to almost $50 \%$ of their initial concentration within the first 2-3 weeks following OMW application to soil (Saadi et al., 2007a; Sierra et al., 2007; Tsiknia et al., 2014). No such effect was observed when OMW was applied in the winter season (Steinmetz et al., 2015), not even in a depth of $2 \mathrm{~m}$ (Chartzoulakis et al., 2010) after one single OMW application during one year study. On the other hand, soluble phenolic compounds were observed in soil at $1.25 \mathrm{~m}$ depth during the winter season (Sierra et al., 2001) and phenolic monomers were detected at a depth of $1.2 \mathrm{~m}$ one year after OMW spreading on soil (Mekki et al., 2006). Furthermore, phenolic compounds have been found in groundwater (Zenjari and Nejmeddine, 2001), which was attributed to OMW leaching through the soil during the winter season (Boukhoubza et al., 2008), whereas 
lower concentrations of phenolic compounds in groundwater have been noted during the summer season (Spandre and Dellomonaco, 1996).

In addition to phenolic compounds, OMW contains considerable amounts of organic acids such as short chain fatty acids (C2-C8) from microbial metabolism of sugars and carbohydrates, and long chain fatty acids $(\mathrm{C} 16-\mathrm{C} 18)$ from the residual oil (Diamantis et al., 2013). Hydrophobic organic compounds can induce soil water repellency (SWR) (Doerr et al., 2000), and fatty acids are the main components responsible for SWR (Graber et al., 2009). Therefore, OMW can induce soil water repellency as reported by Mahmoud et al. (2010) and lead to preferential flow and surface runoff that may induce or intensify soil erosion. Peikert et al. (2015) demonstrated that the hydrophobizing effect of uncontrolled OMW disposal on soil may accumulate with each new application. The development and persistence of SWR is also influenced by variations in environmental conditions such as temperature (Diehl and Schaumann, 2007) and moisture content (Täumer et al., 2005) and has been correlated to soil properties including organic carbon content and $\mathrm{pH}$ (Lebron et al., 2012).

Many researchers indicated that ambient environmental conditions during OMW disposal on soil play a major role in favoring either beneficial or negative effects of OMW-soil interactions (e.g., Barbera et al., 2013; Mekki et al., 2007; Zenjari and Nejmeddine, 2001). The high temporal and spatial variability of ambient environmental conditions existent in the Mediterranean Basin, as well as the high variability of olive orchard types, may explain the partly contradictory results described above. However, systematic studies on the impact of different environmental conditions on the effects of OMW soil application are still scarce. In a field study comparing different cultivation managements in Israel and West Bank during the summer season, Kurtz et al. (2015) found that the OMW effect in SWR and phenolic compounds were lower in irrigated soil compared to non-irrigated soil due to dilution and leaching of toxic compounds as a subsequent impact of irrigation. Steinmetz et al. (2015) found in a field study after one year of OMW application under semi-arid conditions, that summer application revealed a higher SWR and higher concentrations of phenolic compounds than the winter application due to low biological activity, whereas Di Bene et al. (2013) found no long-term effects neither for OMW application in spring nor in autumn. Thus, understanding of the OMW-soil interactions mechanisms during different seasons or how these mechanisms may be influenced by the season of OMW application are still incomplete.

Therefore, the objectives of this study were to investigate the short and long-term effects of OMW application on soil properties at different depth under different seasons in order to understand the OMW - soil transport and interaction mechanisms.

For this, a field experiment was carried out in a traditional olive orchard under Mediterranean climate characterized by long hot dry summer, and short cool rainy winter in the West Bank over a period of 18 months. We hypothesized that the conditions of soil moisture and ambient temperature during and after OMW application to soil can influence the degree of its overall effects and their persistence. Application during cold and moist conditions (winter) may delay OMW degradation due to low biological activity, and frequent rainfalls may promote leaching of easily soluble compounds into deeper layers. On the other hand, moderate conditions of moisture and temperature (spring) are expected to allow for considerable biological degradation, and result in lower SWR and lower concentrations of phenolic compounds. In the summer, under hot and dry conditions, OMW organic compounds are expected to accumulate due to low biological activity and may consequently induce SWR. Hot and moist conditions (summer + irrigation) are expected to enhance the biological degradation of OMW organic matter and thus to minimize its hydrophobizing and toxic effect.

In order to test these hypotheses, four different OMW applications to soil were administered in a field experiment either in spring, in summer (with and without irrigation), or in winter. The persistence and degree of soil salinity, acidity, content of phenolic compounds as well as SWR have been investigated.

\section{MATERIAL AND METHODS Study site}

The selected field site is typical for olive orchards in the West Bank in terms of soil type, texture and vegetation cover. It is located in the village Bait Reema, $40 \mathrm{~km}$ north of Ramallah city, and $500 \mathrm{~m}$ above sea level, perched on an intermediate saddle point. The terraced hill is covered with olive trees (almost 40-50 trees / ha) dating back to over 100 years under extensive use by local families. The soil is clay loam $(37 \%$ clay, $22 \%$ sand, $41 \%$ silt) and is classified as brown rendzina (Dan and Koyumdjisky, 1963). The field was tilled twice that year prior to the study. The Mediterranean climate is predominantly characterized by long hot dry summer and short cool rainy winter, with an average temperature of $24^{\circ} \mathrm{C}$ and an average annual rainfall of $615 \mathrm{~mm}$. Generally, $70 \%$ of the annual rainfall occurs between November and March (Palestinian Meteorological Department, PMD, 2013).

\section{Field experiment and equipment}

Plots design and distribution

Due to the irregular distribution of olive trees in the field site and the suspected influence of a neighbored rock on subsurface water movement, we conducted a preliminary field characterization, in order to decide for an optimal arrangement of the test plots in the field. Soil $\mathrm{pH}$ and electric conductivity $(E C)$ of samples taken from depths of $0-30 \mathrm{~cm}$, and $30-60 \mathrm{~cm}$ in two transects in northeast-southwest and in east-west directions (Fig. 1) revealed a small, but clear runoff-related gradient in the field perpendicular to the line of a large cliff located $100 \mathrm{~m}$ from the field edge (Fig. S3 in Suppl. Mat.). To avoid potential influences of this gradient on our results, sixteen plots, each with dimensions of $2.5 \mathrm{~m}$ by $3 \mathrm{~m}$ were marked in two rows parallel to the cliff line. The distribution of the OMW treatments among the plots was chosen randomly (Fig. 1).

\section{Field equipment for meteorological variables}

A meteorological station (Umwelt-Geräte-Technik $\mathrm{GmbH}$, Germany) was set up in the field which recorded air temperature, air humidity, rainfall, and wind direction. Further, eight temperature sensors (Umwelt-Geräte-Technik $\mathrm{GmbH}$, Germany) have been installed distributed between treatment and control plots, and soil temperature was monitored hourly at five depths below the ground level $(5,8,15,50$ and $70 \mathrm{~cm})$. In each plot, volumetric soil moisture (vol \%) was monitored on a weekly basis through three access tubes in 10, 20, 30, 50 and $90 \mathrm{~cm}$ depth using a portable PR2/6 moisture probe based on HH2 Moisture Meter Readout Unit (Delta-T Devices Ltd, United Kingdom). 


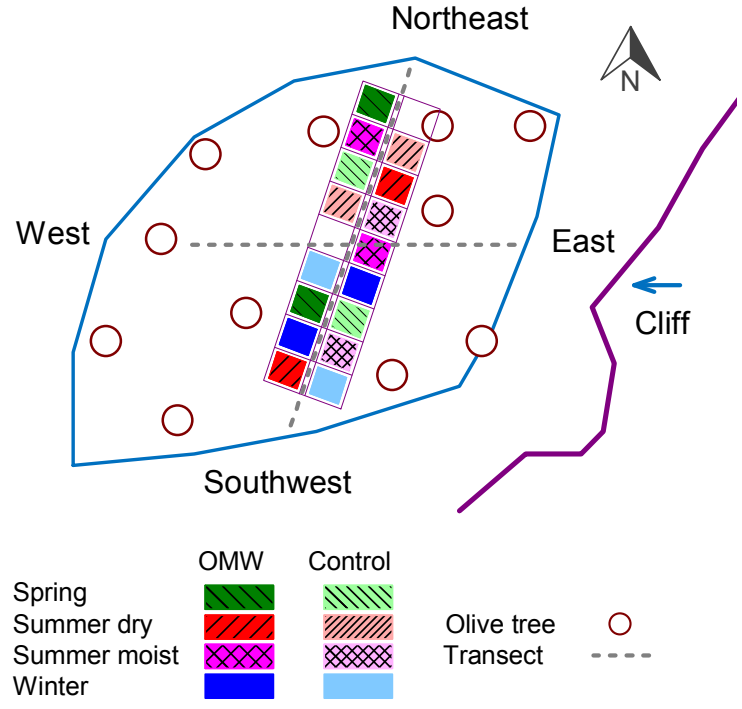

Fig. 1. Location of the transects for site exploration (gray dotted lines) and the plots for the different olive mill waste water (OMW) treatments and their respective control plots.

\section{OMW application to soil and soil sampling}

Four different treatments of OMW application were performed; each conducted on two plots at a time as a single application of $14 \mathrm{~L} \mathrm{~m}^{-2}$ to simulate an extreme situation. Two corresponding control plots were treated with the same amount of tap water. For the spring treatment (SP), the OMW was applied to soil on 12 April 2012. The two summer treatments (dry and moist) were conducted on 13 August 2012. For the dry treatment $\left(\mathrm{SU}_{\mathrm{dry}}\right)$, OMW was applied to non-irrigated soil, while for the moist treatment $\left(\mathrm{SU}_{\text {moist }}\right)$, OMW was applied to the soil which by irrigation had maintained a moisture content between $17-20 \%$ for two weeks prior to application and during the following summer season. For the winter treatment (WI), the OMW was applied to soil on 14 January 2013.

For each plot, soil samples were collected one week prior to OMW application, and 2 days, 3 weeks, 6 weeks, 3 months, 6 months, 9 months, and 12 to 18 months after OMW or tap water application. At each sampling event, samples were collected at five different depths of $0-5 \mathrm{~cm}, 5-10 \mathrm{~cm}, 10-15 \mathrm{~cm}$, $15-25 \mathrm{~cm}$, and $25-35 \mathrm{~cm}$. The samples taken from each depth were pooled from at least five sub-samples from five locations along one line across the plot under consideration (Fig. S4 in Supp. Mat.), and their soil chemical parameters were analyzed as described in the following sections. For an overview of monitoring data and soil samples please refer to Table S1 (Suppl. Mat.).

\section{Analysis of soil properties and OMW General soil characteristics}

Gravimetric water content $(W C)$ was determined on a dry mass basis $\left(38 \mathrm{~h}\right.$ oven-drying at $\left.105^{\circ} \mathrm{C}\right)$. Sieved $(<2 \mathrm{~mm})$ field moist soil samples were extracted with distilled water $(1: 5 \mathrm{w} / \mathrm{v})$, shaken horizontally for $2 \mathrm{hr}$. After paper filtration (Whatman, $150 \mathrm{~mm}$ ), the chloride content was measured by precipitation titration with silver nitrate (Mohr's method) using potassium chromate as an indicator, and electrical conductivity $(E C)$ and $\mathrm{pH}$ was measured according to DIN ISO 11265(1997) and DIN ISO 10390 (2005), respectively.
In order to estimate the degree of soil acidification, a $\mathrm{pH}$ buffering curve for one representative soil sample pooled from all control plots was determined by measuring $\mathrm{pH}$ of an aqueous extract containing increasing amounts of $\mathrm{NaOH}$ and $\mathrm{HCl}$, after an equilibration time of $2 \mathrm{hr}$. Using the buffering curve, the proton $\left(\mathrm{H}^{+}\right)$balance was deduced which is equivalent to the amount of $\mathrm{H}^{+}$that was added to the soil by OMW application to achieve the measured $\mathrm{pH}$-difference between the treated and control soil plots (further details in Suppl. Mat.).

\section{Soluble phenolic compounds}

The total content of soluble phenolic compounds (SPC) was quantified in a soil water extract of air-dried soil samples ( $1: 10 \mathrm{w} / \mathrm{v}$, two hours horizontal shaking) by the Folin-Ciocalteu colorimetric method (Box, 1983). After 30 minutes of incubation, absorbance was measured at $700 \mathrm{~nm}$ using UV-1600/1800 Spectrophotometer (M.R.C., Israel). Tannic acid was used as a standard for calibration curve, and $S P C$ is given in tannic acid equivalents.

\section{Soil water repellency}

In order to characterize the soil water repellency (SWR), water drop penetration time (WDPT) was measured twice for each sampling event. For the first test $\left(W D P T_{\text {Field }}\right)$, fifty water drops of $100 \mu \mathrm{L}$ were placed directly in the field randomly distributed on the undisturbed top soil and the time for complete penetration was determined. For the second test $\left(W D P T_{L a b}\right)$, disturbed air-dried soil samples $(<1 \mathrm{~mm})$ were measured as described by Diehl and Schaumann (2007). The soil was considered water repellent when the WDPT exceeded 5 seconds (Bisdom et al., 1993).

\section{Pore size distribution and hydraulic potential gradient}

In order to determine soil hydraulic properties of the experimental field and to estimate the direction of water transport at selected time points, proton nuclear magnetic resonance $\left({ }^{1} \mathrm{H}-\right.$ NMR) relaxometry was performed for one representative pooled soil sample in triplicate using a Bruker Minispec MQ (Bruker, Karlsruhe, Germany) at a magnetic field strength of $0.176 \mathrm{~T}$ (proton Larmor frequency of $7.5 \mathrm{MHz}$ ). A CarrPurcell-Meiboom-Gill (CPMG) pulse sequence was used to obtain T2 and the corresponding relaxation rates of the water protons in the samples (Jaeger et al., 2009; Meiboom and Gill, 1958). Pore size distribution was determined following the procedure described in Meyer (2015). The pore size distribution was converted into a water retention curve (matric potential as a function of volumetric water content) using Young-LaPlace equation. From this curve, the respective matric potential could be obtained from measured volumetric water contents in the field. With these matric potentials, under consideration of the differences in gravimetric potential, the hydraulic potential gradients between the depths of water content measurement have been calculated for selected time points. This estimation assumed equal bulk density and texture for the whole profile. Further, hydrostatic pressure from water ponding on the soil surface during heavy rain events was not considered. Thus, this estimation is rather rough and might have led to underestimation of the matric potential gradients at high water contents and the data basis is not detailed enough for being able to account for hysteresis. However, it gives an overview of the water flow direction. 


\section{OMW characterization}

OMW was obtained from an olive mill in Bait Reema. OMW used for $\mathrm{SP}, \mathrm{SU}_{\mathrm{dry}}$ and $\mathrm{SU}_{\text {moist }}$ treatments came from the olive harvesting seasons of 2011/2012, whereas the OMW which was used for WI application came from the olive harvesting season of 2012/2013. For all treatments, the OMW was stored in polyethylene containers underground in darkness until the time of application. The $\mathrm{pH}, E C$, and $S P C$ in OMW were determined as described above.

\section{Statistical analysis}

Soil chemical properties were determined in three replicate measurements for each pooled soil sample of each of the two replicate treated plots and control plots for the four OMW treatments. All results are depicted as a mean of six values with their respective standard error used as error bars. The average of $\mathrm{pH}$ and standard errors were calculated based on the $\mathrm{H}^{+}$ concentrations and transferred back into $\mathrm{pH}$ values. The data sets were tested for normal distribution using the Shapiro-Wilk test $(\alpha=0.05)$ and visually checked by QQ-Plots using the statistical software R (R Core Team, 2014). Although normality of the most data sets could not be rejected with $p>0.05$, we used the nonparametric Wilcoxon rank sum test (with holm $p$ value adjustment, using software $\mathrm{R}$ ) for pairwise comparison of our data. Differences are supposed to be significant at $p<0.05$. The $\mathrm{H}^{+}$balance calculation required mean values from both treated and both control plots such that the results could not be related to the original 6 replicates and only one mean value remained which could not be tested with the described tests.

\section{RESULTS}

\section{Seasonal changes during the field experiment}

The spring season 2012 (March-June) was characterized by a moderate increase in average air temperature $\left(12\right.$ to $\left.23^{\circ} \mathrm{C}\right)$ and a mean monthly evaporation of $180 \mathrm{~mm}$ (PMD, 2013) causing a moderate soil temperature increase $\left(15\right.$ to $\left.25^{\circ} \mathrm{C}\right)$ and moderate $W C$ drop (15 to $12 \%$ ) in the top soil (Fig. $2 \mathrm{a}-\mathrm{c}$ ).

During this period, the $\mathrm{pH}$ in the control soil decreased from 8.3 to 7.7 (Fig. 2d). During the summer season 2012 (JuneOctober), the air temperature ranged between 24 and $27^{\circ} \mathrm{C}$ with a mean monthly evaporation of $230 \mathrm{~mm}$ (PMD, 2013), causing a soil temperature rise from 25 to $35^{\circ} \mathrm{C}$ and a $W C$ drop from 8 to $2 \%$ in the top soil (Fig. $2 \mathrm{a}-\mathrm{c}$ ). The corresponding soil $\mathrm{pH}$ increased from 7.7 to 8.6 (Fig. 2d). During the autumn season 2012 (October-November), the air temperature decreased from 24 to $17^{\circ} \mathrm{C}$ with a mean monthly evaporation of $130 \mathrm{~mm}$ (PMD, 2013), causing a soil temperature drop to $\sim 20^{\circ} \mathrm{C}$ and a $W C$ increase from 4 to $20 \%$ due to the start of the rain season (Fig. $2 \mathrm{a}-\mathrm{c}$ ). At the same time, the soil $\mathrm{pH}$ decreased from 8.6 to 8.0 (Fig. 2d). The winter season was characterized by low air temperature in the range of 10 to $14^{\circ} \mathrm{C}$, high rainfall of $550 \mathrm{~mm}$ (Fig. 2a), and low monthly evaporation between 60 to $110 \mathrm{~mm}$ (PMD, 2013). The corresponding soil temperature dropped to $\sim 10^{\circ} \mathrm{C}$ (Fig. $2 \mathrm{~b}$ ). The rain fall replenished the porous structure of the soil profile to reach a $W C$ of $\sim 24 \%$ (Fig. 2c) and the $\mathrm{pH}$ level initially decreased to $\sim 7.6$ in January and then increased to $\sim 8.2$ in February (Fig. 2d).

In comparison to 2012, 2013 witnessed higher rainfall in the spring season, a comparable summer, but a drier autumn. In the winter season $2013 / 2014,86 \%$ of the rainfall was concentrated
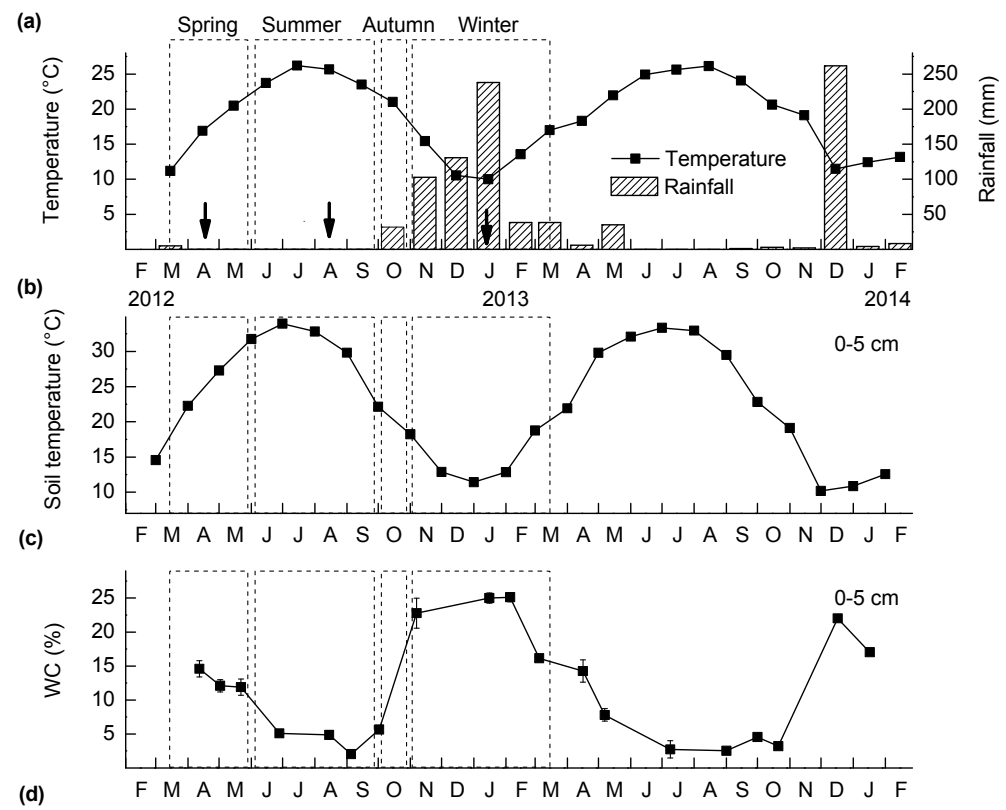

(d)

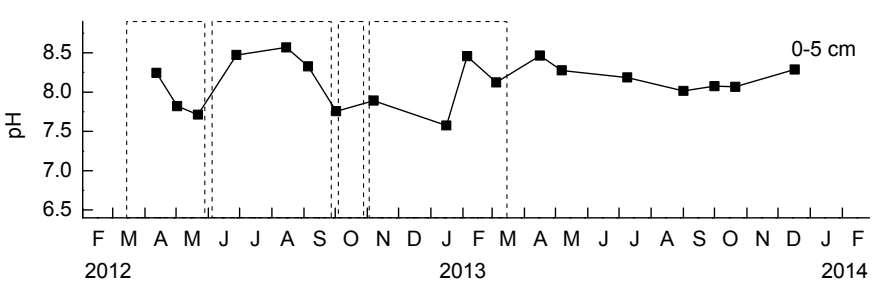

Fig. 2. Monthly average of (a) air temperature and rainfall, (b) seasonal variations in soil temperature, (c) seasonal variations in gravimetric soil water content $(W C)$, and (d) seasonal variation in soil $\mathrm{pH}$ in the field experiment during 18 months in $0-5 \mathrm{~cm}$ depth of control plots. Data points in (b) are the mean values of hourly measurements, in (c) and (d) are the mean of 18 values of 6 control plots except the irrigated plot with error bars representing standard error. The arrow $(\downarrow)$ indicates the date of olive mill waste water (OMW) application to soil. 
in December 2013 (Fig. 2a), resulting in a soil $W C$ of $20 \%$ in the top layer (Fig. 2c). At the end of this season, the pH level remained between 8.0 and 8.5 (Fig. 2d). These seasonal changes in soil temperature and soil moisture were also observed in the treatment plots in deeper soil layers, however, short-term fluctuations in air temperature and rain or irrigation events were reflected with decreasing degree with increasing soil depth (Fig. S7 and S8 in Suppl. Mat.).

The observed seasonal changes in $\mathrm{pH}$ levels on the control soils indicate changing degree of proton releasing processes such as microbial and root activities, which tend to be higher in spring and autumn seasons, due to biologically favourable conditions i.e., soil moisture and temperature. However, the dryness of the summer months and the cold weather in winter, tend to reduce microbial and root activities and with this the proton releasing processes due to less biological favorable conditions in these seasons.

\section{Conditions before OMW application \\ Soil chemical properties}

The spring treatment (SP) was performed, into relatively moist soil, with a $W C$ of $15 \%$ at the top layer, and an increasing $W C$ up to $\sim 35 \%$ at $90 \mathrm{~cm}$ depth (Fig. 3a), at moderate soil temperatures of $\sim 18^{\circ} \mathrm{C}$ down to $70 \mathrm{~cm}$ (Fig. $3 \mathrm{~b}$ ). $E C$ was low with $135 \pm 6 \mu \mathrm{S} \mathrm{cm}^{-1}$ in the top layers dropping to $100 \pm 6 \mu \mathrm{S} \mathrm{cm}^{-1}$ at $35 \mathrm{~cm}$ depth (Fig. 3c). The pH levels were of comparable with $8.3 \pm 0.1$ down to $35 \mathrm{~cm}$ depth (Fig. $3 \mathrm{~d}$ ).

The two summer treatments were performed in August 2012, at a high air temperature of $27^{\circ} \mathrm{C}$. The corresponding soil temperature was $32^{\circ} \mathrm{C}$ in the top layers, decreasing to $29^{\circ} \mathrm{C}$ at $70 \mathrm{~cm}$ depth (Fig. 3b). $W C$ increased from $5 \%$ in the top layer to $20 \%$ at $90 \mathrm{~cm}$ depth in the non-irrigated plots $\left(\mathrm{SU}_{\mathrm{dry}}\right)$, whereas the $W C$ of the irrigated plots $\left(\mathrm{SU}_{\text {moist }}\right)$ was found to be almost uniform at $\sim 20 \%$ for the same soil depths (Fig. 3a). For both the $E C$ was comparable to that found in the SP plots (Fig. 3c). The $\mathrm{SU}_{\text {dry }}$ plots also had $\mathrm{pH}$ values comparable to that of the SP plots (Fig. 3d). In contrast, $\mathrm{SU}_{\text {moist }}$ plots showed increased $\mathrm{pH}$ values up to $8.7 \pm 0.1$, due to the daily administered irrigation for two weeks prior to OMW application (Fig. 3d).

Winter treatment (WI) was performed in January 2013, at the highest monthly rainfall of $288 \mathrm{~mm}$, and the lowest monthly average air temperature of $10^{\circ} \mathrm{C}$. The corresponding soil temperature was $8^{\circ} \mathrm{C}$ at the top layers and $12^{\circ} \mathrm{C}$ at $70 \mathrm{~cm}$ depth (Fig. 3b). The $W C$ was $\sim 30 \%$ at the top layers and $\sim 35 \%$ at $90 \mathrm{~cm}$ depth (Fig. 3a). A strong seasonal effect was observed in the soil pH, which dropped to $7.4 \pm 0.05$ in winter (Fig. 3d) and in the $E C$ value which reduced to $90 \pm 5 \mu \mathrm{Scm}^{-1}$ in comparison to $\mathrm{SU}_{\text {moist, }}, \mathrm{SU}_{\text {dry }}$ and SP plots (Fig. 3c).

The concentrations of SPC were uniform at $20 \pm 5 \mathrm{mg} \mathrm{kg}^{-1}$ for the whole soil profile prior to OMW application, irrespective of the season, representing a natural background concentration. The soil was wettable before the OMW application, with a $W D P T_{L a b}$ and $W D P T_{\text {Field }}$ below $5 \mathrm{~s}$ throughout the whole soil profile, except for the top soil of WI plots, in which $W D P T_{\text {Field }}$ was $\sim 20 \mathrm{~s}$, indicating low infiltration rate due to pore saturation (Hillel, 2003).

One week before any application, the differences in temperature, $W C, \mathrm{pH}, E C$ and $S P C$ between the two treatment plots and the two corresponding control plots, were within the range of the standard errors of replicates from each plot, and much smaller than the observed seasonal and depth dependent variations of these parameters (Fig. 3). Thus, treatment and control plots are comparable for these parameters, such that all observed

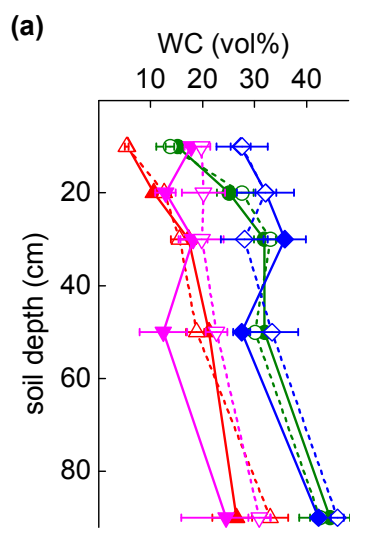

(c)

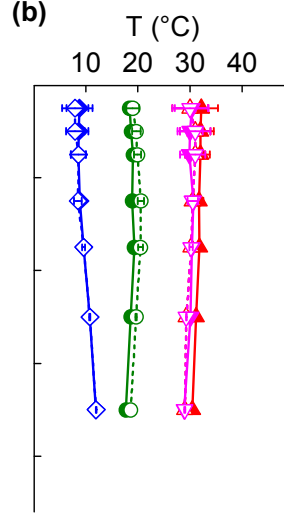

(d)
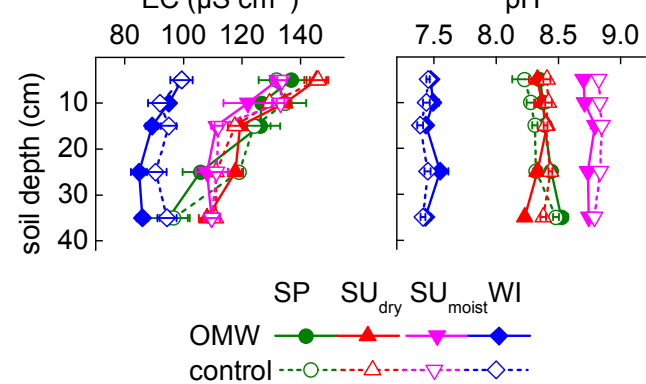

Fig. 3. Average of (a) volumetric soil water content (WC), (b) soil temperature $(T)$, (c) electrical conductivity $(E C)$, and (d) $\mathrm{pH}$, measured one week prior to olive mill wastewater (OMW) or tap water application (control) for spring (SP), summer without irrigation $\left(\mathrm{SU}_{\mathrm{dry}}\right)$, summer with irrigation $\left(\mathrm{SU}_{\text {moist }}\right)$, winter $(\mathrm{WI})$ treatment plots and the respective control plots as a function of soil depth. Data points are mean of six values of two plots for each treatment and two plots for each control with error bars representing standard error, except for $b$ ), where data points are means of hourly measurements over $24 \mathrm{~h}$.

differences after application to be presented in the following sections can be solely attributed to the effect of OMW.

\section{Hydraulic properties}

One important aspect of which is subject to significant seasonal variations, as shown above, is the distribution of water and its transport within the soil profile. Therefore, we estimated the gradient of the hydraulic potential for the $W C$ measurements above (Fig. S5 in Suppl. Mat.). Negative hydraulic gradients indicate an upward directed matric driven water flow, whereas positive gradients indicate a downward directed gravitation driven water flow. For both $\mathrm{SU}_{\text {dry }}$ and SP plots the hydraulic gradient indicates that during spring and summer seasons, down to at least $20 \mathrm{~cm}$ depth, an upward transport by capillary rise is a highly relevant process (Fig. S5 in Suppl. Mat.). This is further underlined by the high evaporation rates in these periods, which range from $180 \mathrm{~mm}$ in April to $250 \mathrm{~mm}$ in August, resulting in daily evaporation rates of $6-8 \mathrm{~mm}$.

In contrast to that, irrigation in summer induced a more complicated hydraulic pattern. The hydraulic gradient in $\mathrm{SU}_{\text {moist }}$ profile indicates a downward movement of water towards $20 \mathrm{~cm}$ whereas from the depth of $30 \mathrm{~cm}$ both, an upward movement towards $20 \mathrm{~cm}$ and a downward movement of water towards $50 \mathrm{~cm}$ are expected.

The WI plots reveal no significant positive or negative hydraulic gradients within the whole profile down to $90 \mathrm{~cm}$ which 
indicates an equilibrium state due to the water saturation from rain water. This is further supported by the low infiltration rate leading to the elevated $W D P T_{\text {Field }}$ on these plots.

\section{OMW quality}

OMW pH and $E C$ for the season 2011/2012 were comparable to that in the season $2012 / 2013$ with $E C$ values of $\sim 10.8 \pm 0.2 \mathrm{mS} \mathrm{cm}^{-1}$ and $\mathrm{a} \mathrm{pH}$ of $4.6 \pm 0.1$. The longer the storage period of the OMW before its application to the soil, the more significant are the changes expected in its quality (Saadi et al., 2007b). Therefore, the OMW quality in term of $S P C$ concentration was closely monitored during storage. The $S P C$ concentrations in OMW at the time of SP application (4 months storage), $\mathrm{SU}_{\mathrm{dry}}$ and $\mathrm{SU}_{\text {wet }}$ application (8 months storage), and WI application (2 months storage) of $5.3 \pm 0.2,5.7 \pm 0.2$ and $5.4 \pm 0.2 \mathrm{~g} \mathrm{~L}^{-1}$, respectively, differed only in the range of the standard error of measurement. Consequently, it can be inferred that the change in the quality of OMW during storage with respect to $S P C$ was negligible and the observed differences after OMW application are unlikely to have been influenced by the age and/or quality of the OMW applied.

\section{Short-term effects two days after OMW application to soil}

Generally, the OMW application to soil increased $E C, S P C$, and $W D P T_{L a b}$ and reduced soil $\mathrm{pH}$ with respect to control plots (Fig. 4). These observed short-term effects are in agreement with other studies and can be related to the acidic nature of OMW (Di Bene et al., 2013; Di Serio et al., 2008; Kavvadias et al., 2010), its high salinity (e.g., Mekki et al., 2009; Moraetis et al., 2011; Sierra et al., 2007), and its high content of phenolic compounds (Chartzoulakis et al., 2010; Zenjari and Nejmeddine, 2001)

Nevertheless, the extent of these effects and their reach with respect to depth varied among the four OMW treatments and among the parameters (Table S2 in Suppl. Mat.).

The increase in $E C$ in the top layer was higher after SP, $\mathrm{SU}_{\mathrm{dry}}$ and WI treatments with comparable $E C$ values of $638 \pm 12 \mu \mathrm{S} \mathrm{cm}^{-1}$ than after $\mathrm{SU}_{\text {moist }}$ treatment with $E C$ values of $250 \pm 10 \mu \mathrm{S} \mathrm{cm}^{-1}$ (Fig. 4a). The $E C$ differences between treated and control plots were significant $(p<0.01)$ after $\mathrm{SP}$ and $\mathrm{SU}_{\mathrm{dry}}$ treatments down to at least $35 \mathrm{~cm}$ depth with $172 \pm 5 \mu \mathrm{S} \mathrm{cm}^{-1}$ and $154 \pm 7 \mu \mathrm{S} \mathrm{cm}^{-1}$, respectively. In contrast, significant salinization effects $(p<0.01)$ were observed only down to $15 \mathrm{~cm}$ after WI and $\mathrm{SU}_{\text {moist }}$ treatments with $E C$ values of $115 \pm$ $10 \mu \mathrm{S} \mathrm{cm}^{-1}$ and $121 \pm 2 \mu \mathrm{S} \mathrm{cm}^{-1}$, respectively. The highest short-term effect on $\mathrm{pH}$ in the top layer with respect to control plots was found after SP treatment with a $\mathrm{pH}$ reduction by $0.7 \pm 0.06$ units, followed by WI treatment with a $\mathrm{pH}$ reduction by $0.6 \pm 0.01$ units, whereas $\mathrm{SU}_{\text {dry }}$ and $\mathrm{SU}_{\text {moist }}$ treatments caused a lower short-term $\mathrm{pH}$ reduction by $0.4 \pm 0.01$ and $0.3 \pm 0.01$ units, respectively (Fig. 4b). A significant $\mathrm{pH}$ reduction $(p<0.01)$ reached deeper soil layers to a depth of at least $35 \mathrm{~cm}$ after $\mathrm{SU}_{\mathrm{dry}}$ and WI treatments, whereas it reached only a depth of $10 \mathrm{~cm}$ for SP $(p<0.05)$, and $25 \mathrm{~cm}$ for $\mathrm{SU}_{\text {moist }}$ treatments $(p<0.01)$. Because $\mathrm{pH}$ is a decimal logarithmic value, $\mathrm{pH}$ differences are indicative for the factor between two $\mathrm{H}^{+}$concentrations. Furthermore, in different $\mathrm{pH}$ ranges, different soil buffer systems will influence the reaction on acidification. A better picture of the acidification effect of OMW application separately from natural $\mathrm{pH}$ dynamics caused by seasonal effects (as indicated in the control soils in section results of seasonal changes during the field experiment) and under consideration of the buffer systems in the respective $\mathrm{pH}$ range, is given by the proton balance (for details see Suppl. Mat.). A comparably strong short-term acidification effect in the top soil layer was observed after WI and SP treatments with $\mathrm{H}^{+}$surplus of $0.15 \pm 0.03 \mathrm{~mol} \mathrm{~kg}^{-1}$ which reached down to $35 \mathrm{~cm}$ depth, whereas no such effect was detectable after $\mathrm{SU}_{\text {moist }}$ and $\mathrm{SU}_{\text {dry }}$ treatments (Fig. 4c).

The highest $S P C$ concentration in the top soil layer was found after WI and $\mathrm{SU}_{\text {dry }}$ treatments (Fig. 4d) with concentrations of $370 \pm 10$ and $260 \pm 13 \mathrm{mg} \mathrm{kg}^{-1}$, respectively, whereas it was lower after $\mathrm{SP}$ and $\mathrm{SU}_{\text {moist }}$ treatments, with values of $135 \pm 3 \mathrm{mg} \mathrm{kg}^{-1}$ and $60 \pm 7 \mathrm{mg} \mathrm{kg}^{-1}$, respectively. The differences between treated and control plots were significant $(p<0.05)$ after all treatments down to at least $35 \mathrm{~cm}$ depth. Nevertheless, after $\mathrm{SU}_{\text {dry }}, \mathrm{SU}_{\text {moist }}$ and SP treatments, SPC concentrations continuously decreased with depth to $43 \pm 5,38 \pm 5$ and $34 \pm 5 \mathrm{mg} \mathrm{kg}^{-1}$, respectively, at $35 \mathrm{~cm}$. In contrast, $S P C$ concentration after WI treatment only decreased from 5 to $10 \mathrm{~cm}$ depth and remained nearly constant in the range of $10-$ $35 \mathrm{~cm}$ depths with $166 \pm 10 \mathrm{mg} \mathrm{kg}^{-1}$ (Fig. 4d). The $S P C$ mass balance evaluation showed that, depending on the treatment, only a part of the SPC applied with the OMW was still located in the upper $35 \mathrm{~cm}$ : Only for the winter treatment $\sim 100 \%$ of the $S P C$ was still located in the upper $35 \mathrm{~cm}$, whereas for the $\mathrm{SU}_{\text {dry }}$ treatment, the recovery in the upper $35 \mathrm{~cm}$ was $\sim 60 \%$, and for SP and $\mathrm{SU}_{\text {moist }}$, it was only $27 \%$ and $20 \%$, respectively.

The water drop penetration times were elevated after $\mathrm{SU}_{\text {moist }}$, $\mathrm{SU}_{\text {dry }}$ and WI treatment to $W D P T_{L a b}$ values of $20 \pm 5 \mathrm{~s}, 38 \pm 3 \mathrm{~s}$ and $120 \pm 5 \mathrm{~s}$, respectively, which suggests that the OMW application induced moderate water repellency in all treatments except the SP treatment which revealed with $0 \mathrm{~s}$ the same $W D P T_{L a b}$ as all control plots (Fig. 4e). Water repellency in $10 \mathrm{~cm}$ depth was only detected after $\mathrm{SU}_{\text {dry }}$ treatment with a $W D P T_{L a b}$ of $13 \pm 2 \mathrm{~s}$. Thus, the top soil of the WI plots exhibited the highest short-term $W D P T_{L a b}$ and $S P C$ among all treatments. The $W D P T_{L a b}$ probably increased due to the accumulation of hydrophobic substances from OMW application at the surface as indicated, for example, by the increased $S P C$.

The $S P C$ mass balance suggests a significant loss of OMWderived compounds already during the first two days of OMWsoil contact from the top $35 \mathrm{~cm}$. This raises questions on the mechanisms for OMW distribution within the soil profile and the influence, if any, of ambient conditions on this distribution. In order to separate the transport effect from effects of sorption and degradation, the chloride $\left(\mathrm{Cl}^{-}\right)$present in OMW was considered as an indicator for water movement respective the position of the water at the time of sampling (Fig. 4f). The highest $\mathrm{Cl}^{-}$concentration in the top layer was found after $\mathrm{SU}_{\text {dry }}$ treatment $\left(760 \pm 13 \mathrm{mg} \mathrm{kg}^{-1}\right)$, whereas the lowest concentration was found after $\mathrm{SU}_{\text {moist }}$ treatment $\left(280 \pm 15 \mathrm{mg} \mathrm{kg}^{-1}\right)$. The $\mathrm{Cl}^{-}$ concentrations after SP and WI treatments were $360 \pm 40$ and $390 \pm 8 \mathrm{mg} \mathrm{kg}^{-1}$, respectively. Differences in $\mathrm{Cl}^{-}$concentration between treated and control plots were significant $(p<0.05)$ until depths of $35 \mathrm{~cm}$ after $\mathrm{SP}$ and $\mathrm{SU}_{\text {dry }}$ treatments, but only to depths of $10 \mathrm{~cm}$ for $\mathrm{SU}_{\text {moist }}$ and $15 \mathrm{~cm}$ for WI treatments. This would suggest that at the time of sampling the aqueous phase of the OMW was located only in the top $15 \mathrm{~cm}$ for $\mathrm{SU}_{\text {moist }}$ and WI treatments, whereas it distributed to at least $35 \mathrm{~cm}$ depth for SP and $\mathrm{SU}_{\mathrm{dry}}$ treatments. Unfortunately the calculated mass balances with respect to $\mathrm{Cl}^{-}$(under consideration of the $\mathrm{Cl}^{-}$ content in the controls) would indicate that far more than $100 \%$ of the OMW-derived $\mathrm{Cl}^{-}$is located in the top $35 \mathrm{~cm}$ layer. These differences are most probably due to overlay with soilinherent $\mathrm{Cl}^{-}$and render a reliable mass balance assessment for OMW derived $\mathrm{Cl}^{-}$with respect to control values impossible. 
(a)

$\mathrm{EC}\left(\mu \mathrm{S} \mathrm{cm}{ }^{-1}\right)$

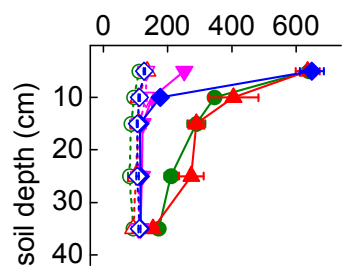

(c) $\mathrm{H}^{+}$balance $\left(\mathrm{mol} \mathrm{kg}^{-1}\right)$

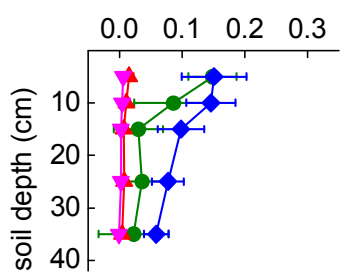

(e)

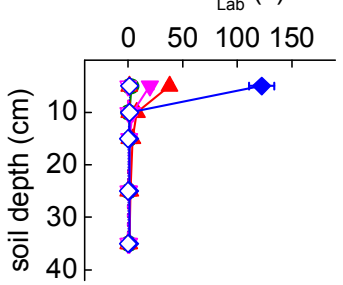

(b) $\mathrm{pH}$

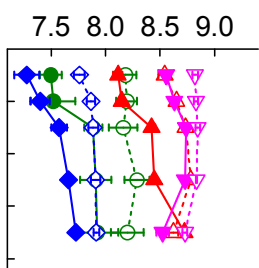

(d) $\mathrm{SPC}\left(\mathrm{mg} \mathrm{kg}^{-1}\right)$

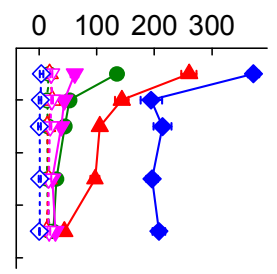

(f) Cloride $\left(\mathrm{mg} \mathrm{kg}^{-1}\right)$

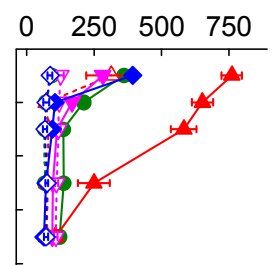

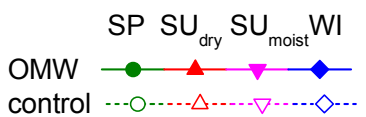

Fig. 4. Average of (a) electrical conductivity $(E C),(\mathbf{b}) \mathrm{pH},(\mathbf{c}) \mathrm{H}^{+}$ balance between control and treated soil, (d) concentration of water soluble phenolic compounds $(S P C)$, (e) water drop penetration time of disturbed samples $\left(W D P T_{L a b}\right)$, and (f) chloride concentration for spring (SP), summer without irrigation $\left(\mathrm{SU}_{\mathrm{dry}}\right)$, summer with irrigation $\left(\mathrm{SU}_{\text {moist }}\right)$, and winter (WI) olive mill waste water (OMW) treatment plots and the respective control plots as a function of soil depth. Data points are means of six values of two plots for each treatment and two plots for each control with error bars representing standard error.

\section{Long-term effects of OMW application in soil under different seasons}

The strongest long-term changes in soil properties following OMW application were observed in the upper soil layer $(0-$ $5 \mathrm{~cm}$ depth). The extent of effects generally decreased with increasing soil depth and after the first rain season following the application (Fig. S9 to S13 in Suppl. Mat.). Therefore, in this chapter, we will focus on the time-dependent variations of $E C, S P C, W D P T_{\text {Field }}$, and $\mathrm{H}^{+}$balance in the top $5 \mathrm{~cm}$.

Generally, the extent of effects of OMW application to soil decreased during the spring season (SP treatment) and increased during the summer season ( $\mathrm{SP}, \mathrm{SU}_{\mathrm{dry}}$ and $\mathrm{SU}_{\text {moist }}$ ), but almost completely disappeared in all OMW-treated plots after the following rainy winter season (Fig. 5).

$E C$ and $S P C$ in SP treated plots significantly decreased $(p<0.05)$ to $50 \%$ within six weeks during spring season 2012 (Fig. 5a-c, Table S3 in Suppl. Mat.). A secondary significant increase $(p<0.05)$ in $E C$, interpreted as an increase in salinity, was observed in both $\mathrm{SP}$ and $\mathrm{SU}_{\text {dry }}$ treated plots during the summer season 2012 (Fig. 5a and Table S3 in Suppl. Mat.). This resulted in maximum $E C$ values of $770 \pm 20 \mu \mathrm{S} \mathrm{cm}^{-1}$ in the SP plots, and $830 \pm 40 \mu \mathrm{S} \mathrm{cm}^{-1}$ in the $\mathrm{SU}_{\text {dry }}$ plots at the end of same summer season. Also, the $S P C$ significantly increased $(p<0.05)$ in these plots (Fig. 5b, Table S3 in Suppl. Mat.). However, the increase was less pronounced in SP than in $\mathrm{SU}_{\text {dry }}$ treated plots with a maximal concentration of $123 \pm 14$ and $332 \pm 17 \mathrm{mg} \mathrm{kg}^{-1}$, respectively. In contrast, the EC slightly increased in $\mathrm{SU}_{\text {moist }}$ treated plots up to $350 \pm 50 \mu \mathrm{S} \mathrm{cm}^{-1}$ during the summer (Fig. 5a), while the $S P C$ gradually decreased $(p<0.05$, Table S3 in Suppl. Mat.) to values similar to control plots within six weeks (Fig. 5b). During the same period, the $\mathrm{H}^{+}$ balance increased in the $\mathrm{SP}, \mathrm{SU}_{\mathrm{dry}}$ and $\mathrm{SU}_{\text {moist }}$ treated plots, which indicates a secondary acidification effect of the OMW application, albeit at varying degrees of severity depending on the time of application (Fig. 5c). The strongest secondary acidification was observed in the $\mathrm{SU}_{\text {dry }}$ treated plots with a maximum additional $\mathrm{H}^{+}$generation of $0.32 \pm 0.06 \mathrm{~mol} \mathrm{~kg}^{-1}$, while less, but longer lasting surplus $\mathrm{H}^{+}$were found in $\mathrm{SU}_{\text {moist }}$ and $\mathrm{SP}$ treated plots with peak values of $0.15 \pm 0.08$ and $0.11 \pm 0.02 \mathrm{~mol} \mathrm{~kg}^{-1}$ in November 2012 and January 2013, respectively.

The $W D P T_{\text {Field }}$ also increased in both $\mathrm{SU}_{\text {dry }}$ and SP treated plots during the summer season, where it reached the maximum values of $13 \pm 2 \mathrm{~s}$ and $9 \pm 2 \mathrm{~s}$, respectively (Fig. 5d), however the difference was only in $\mathrm{SU}_{\text {dry }}$ treated plots significant $(p<0.01$, Table S3 in Suppl. Mat.). This trend was also observed for the $W D P T_{L a b}$ of $46 \pm 2 \mathrm{~s}$ and $10 \pm 2 \mathrm{~s}$ for the $\mathrm{SU}_{\mathrm{dry}}$ and SP plots, respectively. However, in the $\mathrm{SU}_{\text {moist }}$ treated plots, $W D P T_{\text {Field }}$ significantly decreased $(p<0.01$, Table S3 in Suppl. Mat.) during the summer season 2012.

During the winter season, the $S P C$ values significantly decreased $(p<0.05)$ in $\mathrm{SP}, \mathrm{SU}_{\text {dry }}$ and WI treated plots to minimal concentrations of $27 \pm 2,72 \pm 11$, and $75 \pm 6 \mathrm{mg} \mathrm{kg}^{-1}$ respectively, in January and February 2013 (Fig. 5b, Table S3 in Suppl. Mat.). The soil in $\mathrm{SU}_{\text {moist }}$ treated plots was already completely wettable before the winter season 2012/2013, whereas the $W D P T_{\text {Field }}$ for $\mathrm{SU}_{\text {dry }}$ and SP plots disappeared in the end of winter 2013 (Fig. 5d, Table S3 in Suppl. Mat.). Also for the WI plots, which exhibited the highest short-term $W D P T_{\text {Field }}$, values, significantly decreased ( $p<0.01$, Table S3 in Suppl. Mat.) during the winter season 2012/2013.

In $\mathrm{SU}_{\mathrm{dry}}$ treated plots, the secondary acidification effect disappeared at the beginning of the winter season 2012/2013, while in the $\mathrm{SU}_{\text {moist }}$, SP and WI treated plots, it decreased and disappeared ( $p>0.05$, Table S4 in Suppl. Mat.) in spring 2013 (Fig. 5c). Also, the $E C$ differences between treated and control plots ( $p>0.05$, Table S5 in Suppl. Mat.) disappeared for SP (Fig. 5a), while in $\mathrm{SU}_{\text {dry }}, \mathrm{SU}_{\text {moist }}$ and WI plots $E C$ values of the upper soil layers $(10-15 \mathrm{~cm}$ depth) were slightly higher than in the control plots.

In the following summer season 2013, no repellency was found in any of the treated plots, whereas a significant $(p<0.05)$ secondary salinization effect was re-observed in the top soil in $\mathrm{WI}$ and $\mathrm{SU}_{\text {dry }}$ plots with $E C$ value of $200 \pm 20 \mu \mathrm{S} \mathrm{cm}^{-1}$ (Fig. 5a and Table S4 in Suppl. Mat.). Furthermore, also $S P C$ remained significantly elevated with respect to control in all treated plots in nearly all depths (Table S4 in Suppl. Mat.). However, $S P C$ mass balance (down to $35 \mathrm{~cm}$ ) at this time showed, that the highest percentage of $S P C$ applied with the OMW was found in $\mathrm{SU}_{\text {dry }}$ plots with $28 \%$, followed by WI plots with $21 \%$, whereas in $\mathrm{SP}$ and $\mathrm{SU}_{\text {moist }}$ plots only $18 \%$ and $13 \%$ of $S P C$, respectively. Although at the end of the experiment in winter 2013/14, EC and SPC were still significantly higher than in the respective control plots (Table S4 in Suppl. Mat.), these differences were with $3-15 \mu \mathrm{S} \mathrm{cm}^{-1}$ and 21-38 $\mathrm{mg} \mathrm{kg}^{-1}$ negligible with respect to the seasonal fluctuations of these parameters on the control plots. 
(a)

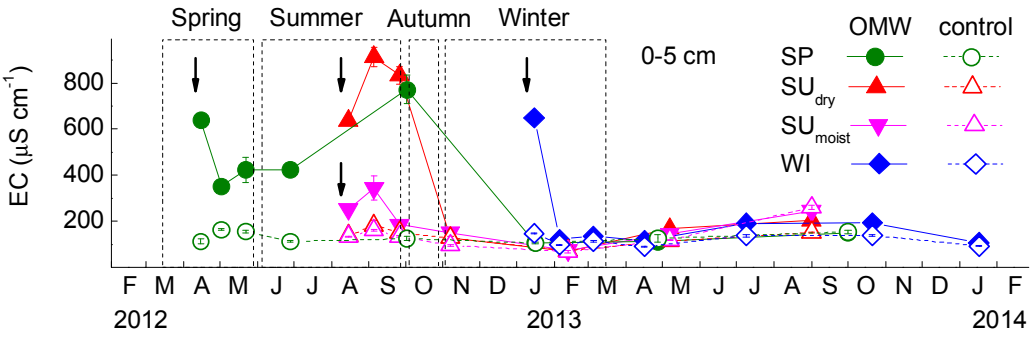

(b)

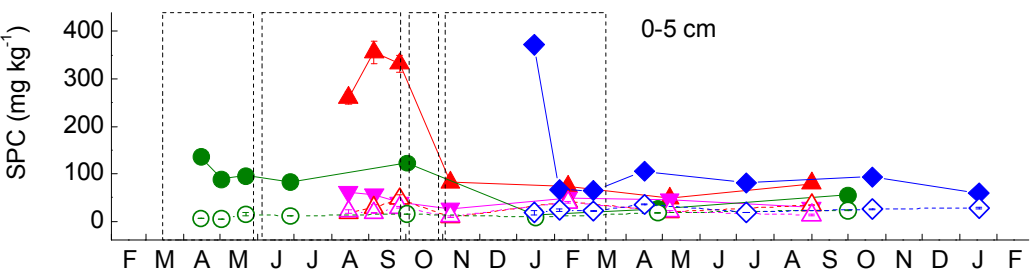

(c)
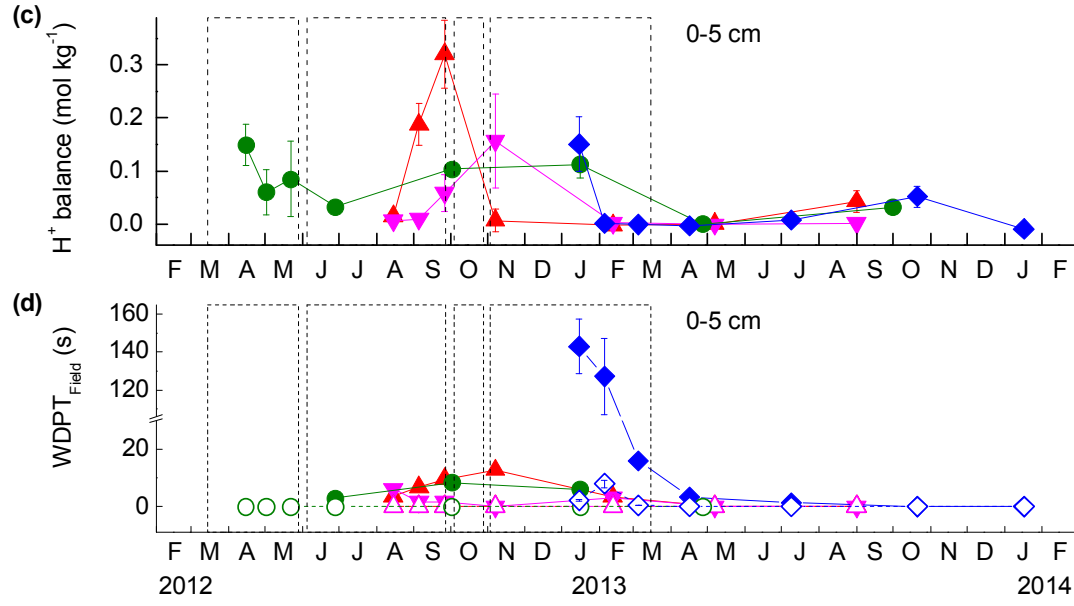

Fig. 5. Average of (a) electrical conductivity $(E C)$, (b) concentration of water soluble phenolic compounds $(S P C)$, (c) $\mathrm{H}^{+}$balance between control and treated soil, and (d) water drop penetration time in field $\left(W D P T_{\text {Field }}\right)$, for the top soil $(0-5 \mathrm{~cm})$ as a function of time for spring $(\mathrm{SP})$, summer without irrigation $\left(\mathrm{SU}_{\mathrm{dry}}\right)$, summer with irrigation $\left(\mathrm{SU}_{\text {moist }}\right)$ and winter $(\mathrm{WI})$ treatment plots. First results are obtained 2 days after olive mill waste water (OMW) application to soil $(\downarrow)$. Data points are means of six values of two plots for each treatment and two plots for each control with error bars representing standard error.

\section{DISCUSSION}

\section{Short-term OMW-soil interaction and transport} mechanisms

The results above clearly show that the OMW has reached much deeper depths than expected from the applied amount of $14 \mathrm{~L} \mathrm{~m}^{-2}$. This indicates that preferential flow is effective in all treatments and it cannot be excluded that part of OMW may have reached depths even below $35 \mathrm{~cm}$. The $S P C$ mass balances suggest that preferential flow might be most effective in the $\mathrm{SP}$ and $\mathrm{SU}_{\text {moist }}$ treatments, followed by $\mathrm{SU}_{\mathrm{dry}}$ and then WI treatments. This is especially surprising for $\mathrm{SU}_{\mathrm{dry}}$ treatments because the highest preferential flow would be expected in the driest soil (Hillel, 2003). Therefore, it cannot be excluded that the differences in $S P C$ mass balance between $\mathrm{SP} / \mathrm{SU}_{\text {moist }}$ and $\mathrm{SU}_{\mathrm{dry}}$ are caused by an enhanced microbial degradation of OMW due to favorable moisture and temperature conditions (Chaari et al., 2014). Buchmann et al. (2015) found a reduction of $\sim 40 \%$ for total phenolic compounds within two days during an incubation experiment of OMW treated soil $\left(14 \mathrm{~L} \mathrm{~m}^{-2}, 23 \%\right.$ $W C, 15^{\circ} \mathrm{C}$ ) which suggests that comparable microbial process may explain the difference of $30 \%$ in the $S P C$ recovery between $\mathrm{SP} / \mathrm{SU}_{\text {moist }}$ and $\mathrm{SU}_{\mathrm{dry}}$ in the field experiment.

The deeper penetration depths of SPC, than of $E C$ and $\mathrm{Cl}^{-}$ for $\mathrm{SU}_{\text {moist }}$ and WI points to an enhanced gravitation driven downward transport due to irrigation or rain water because the downward transport of the liquid part of OMW must have been slow enough to allow organic substances like $S P C$ to interact with the soil leading to their retardation but still fast enough to leach inert ions like $\mathrm{Cl}^{-}$from the observed horizons (Chaari et al., 2014). The higher short-term effects on most soil parameters in WI plots with respect to $\mathrm{SU}_{\text {moist }}$ plots suggest that during winter, the leaching is less effective than during irrigation in summer. This is further supported by the elevated $W D P T_{\text {Field }}$ of $\sim 20 \mathrm{~s}$ of the WI plots already before application which points to a reduced infiltration rate of the OMW with respect to the other treatments due to the higher degree of water saturation (Hillel, 2003) and which did probably not indicate repellency. This is in line with the positive hydraulic gradients in the $\mathrm{SU}_{\text {moist }}$ profile. Further, the nearly constant $S P C$ concentration in the soil profile below $10 \mathrm{~cm}$ depth in the WI plots suggests that the OMW organic matter which accumulated at the soil surface due to the lower infiltration rate may have been continuously releasing $S P C$ into the soil solution which was slowly transported downward.

In contrast to $\mathrm{SU}_{\text {moist }}$ and $\mathrm{WI}$, comparably negative hydraulic gradients in the upper $20 \mathrm{~cm}$ for $\mathrm{SP}$ and $\mathrm{SU}_{\text {dry }}$ indicate that capillary rise dominates the water movement in these horizons. This is further supported by the comparably elevated $E C$ depth profiles with respect to $\mathrm{SU}_{\text {moist }}$. 


\section{Long-term OMW-soil interaction and transport mechanisms}

The secondary increase in salinity and $S P C$ in $\mathrm{SP}$ and $\mathrm{SU}_{\mathrm{dry}}$ plots during the summer season 2012 suggests an upward directed water flow within the soil profile due to evaporation at the surface layer (Magdich et al., 2013) by which OMW compounds migrated upward by capillary action (Steinmetz et al., 2015). This matches with the clearly upward directed hydraulic gradient down to $50 \mathrm{~cm}$ depth in these plots (Fig. S6 in Suppl. Mat.). The comparable salinization effect in $\mathrm{SP}$ and $\mathrm{SU}_{\text {dry }}$ treated plots suggests that the applied salt content was almost completely restored at the soil surface whereas a large part of the applied $S P C$ from the SP plots disappeared. Loss of $S P C$ in SP plots during the summer months due to leaching can be excluded due to the negative hydraulic gradients in the upper $50 \mathrm{~cm}$, such that so the phenomenon could be explained by either incomplete biotic degradation of phenol OMW constitute in the first weeks following the OMW application (Kurtz et al., 2015) and/or incorporation into the organic matter (Saadi et al., 2007b; Sierra et al., 2007) or by sorption to soil particles and reduced mobility allowing part of the $S P C$ to remain in deeper soil layers after the initial transport through preferential flow. However, the current results as they stand cannot distinguish between these feasible processes. Further investigations focusing on the binding mechanism of the phenolic compounds to soil and laboratory incubation studies for the degradation of phenolic compounds (Buchmann et al., 2015) will be required to obtain further evidence for transport, retardation and degradation mechanisms. For example Buchmann et al. (2015) found that during the initial phase of OMW-soil contact under spring conditions, degradation overbalances, whereas, after $\sim 30$ days, part of phenolic compounds becomes physically immobilized and temporarily less bioavailable.

In addition to the dryness, salt accumulation in the soil can reduce microbial activity (Mekki et al., 2009) which may offer an explanation for the persistence of phenolic substances observed in the upper layers in the $\mathrm{SU}_{\text {dry }}$ plots during summer. The highest acidification out of all treated plots was found in $\mathrm{SU}_{\text {dry }}$ plots between August and October 2012 with very low $W C$ and consequently, could not be related to microbial activity and moisture content as in the $\mathrm{SU}_{\text {moist }}$ plots. An alternative explanation for the observed acidification is indicated by the reduced wettability and the deep brown-dark color in the top layers of $\mathrm{SU}_{\mathrm{dry}}$ treated plots during this period. The major components of the colored fraction in OMW are substances of polymeric nature (Hanafi et al., 2011; Kachouri et al., 2005) that are often attributed to oxidation and polymerization products of tannins and have a strong toxic effect on microorganisms (Bhat et al., 1996). It can be deduced that abiotic phenol oxidation and polymerization rather than biotic degradation are at play as shown by Equation (1) and (2).
By oxidation of phenolic substances, oxidants (e.g. iron or manganese oxides) are reduced and protons are released (Eq. 1) which explains the acidification. This is underlined by the observation made by Peikert (2015) that $\mathrm{Mn}^{2+}$ concentration increased during an incubation experiment with OMW treated soil. Due to the polymerization of phenolic substances (Eq. 2), larger and more hydrophobic compounds are expected to be formed which could explain the reduced wettability in $\mathrm{SU}_{\text {dry }}$ plots.

The lower extent of secondary salinization and the decrease of $S P C$ during the summer in $\mathrm{SU}_{\text {moist }}$ plots compared to $\mathrm{SU}_{\mathrm{dry}}$ plots suggest that large parts of the soluble OMW substances which were removed from the observed profile during the first two days were not transported back to the surface via capillary rise. This indicates that the intermittent irrigation leached OMW constituents downwards (Kurtz et al., 2015) and prevented their accumulation at the surface. When looking at the depth profile of the hydraulic gradient (Fig. S6 in Suppl. Mat.) it becomes clear that these compounds must have largely accumulated in $\sim 50 \mathrm{~cm}$ depth, i.e. in the region of minimum water content, as throughout the year the hydraulic gradient in $50-$ $90 \mathrm{~cm}$ depth was directed upwards, suggesting continuous capillary rise in the deeper layers throughout the year. This consequence should be tested in further investigations exploring the $S P C$-depth distribution up to at least $1 \mathrm{~m}$ depth.

The decrease of the $S P C$ in the $\mathrm{SU}_{\text {moist }}$ plots during summer might be caused either by biological degradation, supported by the concomitant acidification and a decrease of SWR (Fig. $5 \mathrm{c}-\mathrm{d}$ ), or by successive downward transport into the deeper layers, with the consequence of accumulation at $\sim 50 \mathrm{~cm}$ as discussed above. Due to the biologically favourable conditions, an, at least, partial degradation is, however, highly probable. Observations of phenolic compounds rapidly reducing in concentration (Di Serio et al., 2008) and degrading (Sierra et al., 2007) under environmental conditions favourable to biological activity have been reported by other researchers (Barbera et al., 2013). However, other fixation mechanisms like sorption which is enhanced in hydrated soil with respect to dry soil (Ochsner et al., 2006) and which have been found by Buchmann et al. (2015), cannot be excluded.

The rapid decrease in $E C, S P C$ and acidification during the rainy winter season in $\mathrm{SP}, \mathrm{SU}_{\mathrm{dry}}$ and WI plots is clearly related to leaching, because it occurred simultaneously for $\mathrm{Cl}^{-}$and at all soil depths (Fig. S14 in Suppl. Mat.). SWR in SP and SU dry plots totally disappeared during the following winter which could be related to hydrolysis reactions mobilizing the polymerized compounds and consequently enabling their leaching. In contrast, the SWR in WI plots could not be related to polymerization but rather to the accumulation of hydrophobic OMW constituents in the top soil layers (Gonzalez-Vila et al., 1995). The latter could not leach out as fast as the most soluble compounds like $S P C$ and $\mathrm{Cl}^{-}$until conditions for microbial degradation of organic constituents improved in spring 2013.<smiles>O=C(O)C1=CC(=O)C(O)=CC1=[P+]=[Pt+2]</smiles>

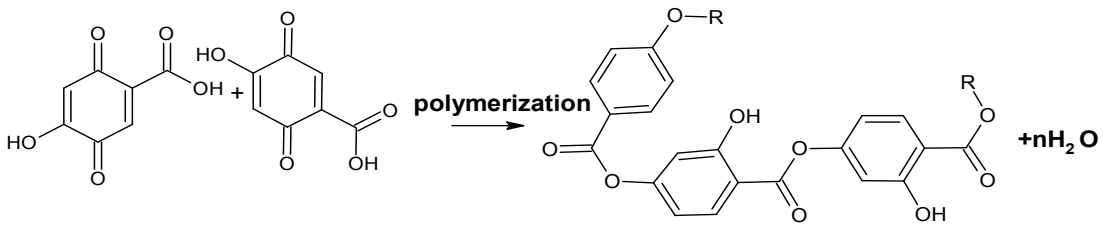




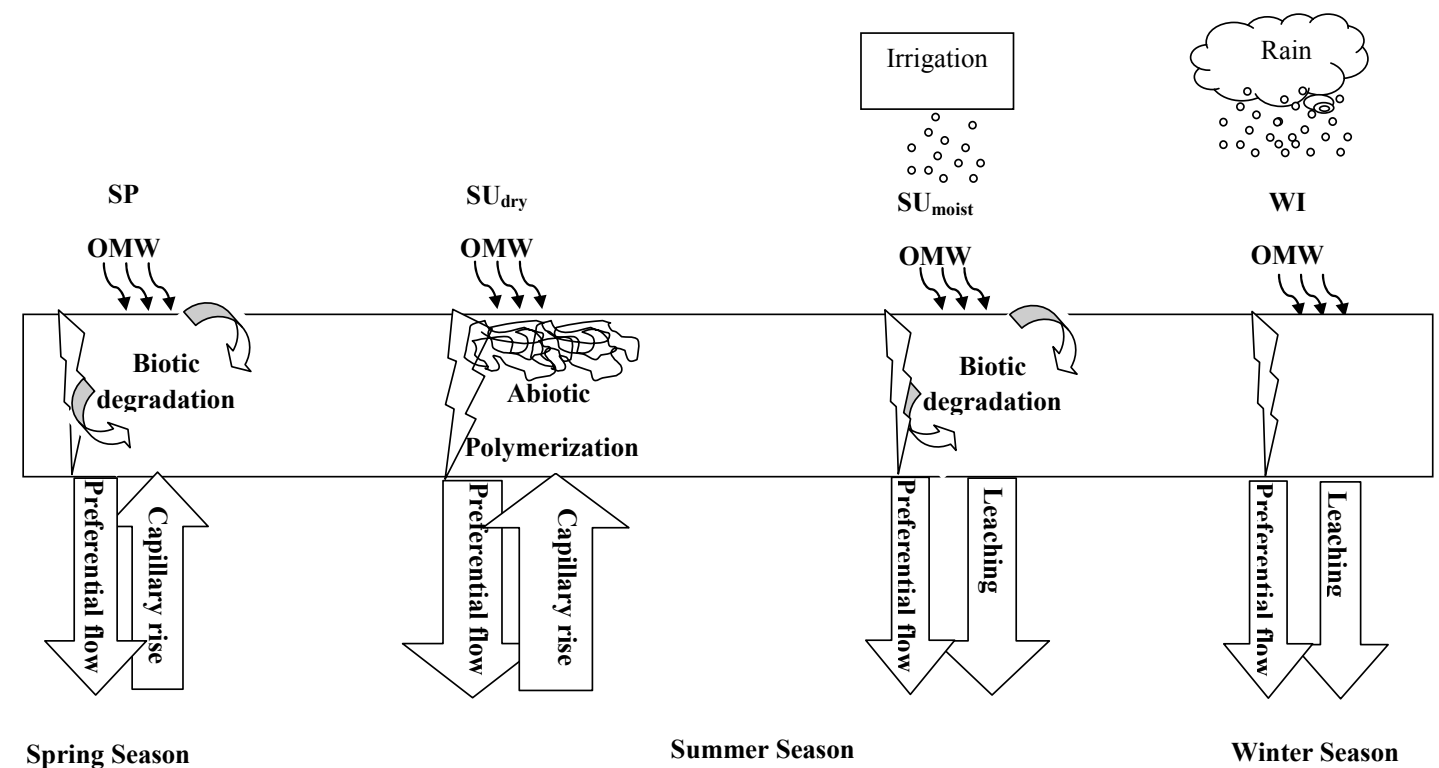

Fig. 6. Combination of our findings on dominant olive mill waste water (OMW) - soil interaction and transport mechanisms for spring $(\mathrm{SP})$, summer without irrigation $\left(\mathrm{SU}_{\mathrm{dry}}\right)$, summer with irrigation $\left(\mathrm{SU}_{\text {moist }}\right)$ and winter $(\mathrm{WI})$ treatment across the different seasons.

The slight increase of EC and SPC during summer 2013 in $\mathrm{SU}_{\mathrm{dry}}$ and WI plots could be attributed to capillary rise and shows that not $100 \%$ of the OMW constituents were immobilized, degraded or leached to the groundwater during the previous seasons. Steinmetz et al. (2015) found comparable results, i.e., no leaching or degradation, but only when OMW was applied during the hot season. In the $\mathrm{SU}_{\text {moist }}$ plots, only elevated $E C$ values but no concomitant elevated $S P C$ contents reappeared in summer 2013. This suggests that part of the organic compounds must have been immobilized or degraded during the previous seasons such that they could not be rise to the surface by capillary action as inorganic salts did in summer 2013.

\section{CONCLUSIONS}

The field experiment clearly demonstrates that each OMW treatment to the soil is dominated by different transport and transformation processes, triggered by the ambient soil moisture and temperature during and after the application. In all seasons, short-term OMW-soil interaction is dominated by preferential flow. However, in spring and summer season subsequent capillary rise is a highly relevant process.

Under the moderate ambient conditions of spring season, biotic degradation of OMW organic compounds is highly probable. However, also, incorporation into the organic matter cannot be excluded. In contrast, high temperature and low soil moisture in the summer season impede biotic degradation and any leaching so the OMW organic compounds rising to the soil surface by capillary action accumulate and polymerize. Irrigation during the summer season may cause leaching of soluble OMW constituents, part of which can intermittently rose back by capillary action to the upper soil layers where biotic degradation is enhanced by favorable moisture conditions. Finally, the winter season is dominated by leaching since the low temperature and high water content in the soil eliminates the biotic degradation of OMW constituents. This shifting in the dominating mechanisms across the different treatment conditions is depicted in Fig. 6 which combines our main findings described above.
The results confirm that the degree of negative effects attributed to salinization, secondary acidification, SPC accumulation and appearance of SWR in soil depends primarily on the time of OMW application to soil and the dominant mode of OMW-soil interaction mechanisms. The most severe effects have to be expected in the hot dry summer and the cold wet winter seasons. Moderate negative effects are expected in the spring season, whereas low negative effects are expected in moist summer season (e.g., irrigation). The persistence of negative effects in the soil with time is more significant the longer the hot and dry conditions last following the OMW application, causing the OMW constituents to accumulate and polymerize without being degraded. Moreover, the composition and concentration of the potentially hazardous OMW residuals in the soil are highly dependent on the time span between the OMW application and the following rain season which leads to leaching of non-degraded constituents of OMW into the deeper soil layers and contamination of groundwater aquifers. Therefore, our findings suggest that summer and winter seasons should be avoided in OMW application to soil due to the high probability of groundwater contamination. This is in agreement with Steinmetz et al. (2015). Although Di Bene et al. (2013) concluded that OMW application in spring and autumn caused no long-term effect, the authors found strong indications for significant leaching, however, their study was limited to $20 \mathrm{~cm}$ depth. In accordance to Barbera et al. (2013), our results confirm that the spring season is the most suitable time for OMW application, especially, if improved by carefully planned irrigation events so as to avoid undesirable leaching of OMW constituents into deeper layers (Kurtz et al., 2015) through preferential flow paths but maintain sufficient moisture to ensure biological degradation activities. In addition, application in spring offers the longest period before the inevitable leaching occurs during the rainy winter season.

However, further studies involving deeper soil layers and groundwater are required to understand how deep the impact of preferential flow reaches and how leaching is triggered by irrigation and precipitation. Further, amount and quality of soil organic matter after OMW application should be investigated in order to understand the mechanisms of biotic degradation under different conditions of OMW application to soil. 
Acknowledgement. This research was conduct within the trilateral project "OLIVEOIL" funded by DFG (SCHA849/13).

\section{REFERENCES}

Amaral, C., Lucas, M.S., Coutinho, J., Crespí, A.L., do Rosário Anjos, M., Pais, C., 2008. Microbiological and physicochemical characterization of olive mill wastewaters from a continuous olive mill in Northeastern Portugal. Bioresour. Technol., 99, 7215-7223.

Barbera, A.C., Maucieri, C., Cavallaro, V., Ioppolo, A., Spagna, G., 2013. Effects of spreading olive mill wastewater on soil properties and crops: a review. Agric. Water Manage., 119, 43-53.

Ben Sassi, A., Boularbah, A., Jaouad, A., Walker, G., Boussaid, A., 2006. A comparison of Olive oil Mill Wastewaters (OMW) from three different processes in Morocco. Process Biochem., 41, 1, 74-78.

Bhat, T.K., Makkar, H.P.S., Singh, B., 1996. Isolation of a tannin protein complex-degrading fungus from faeces of hill cattle. Lett. Appl. Microbiol., 22, 4, 257-258.

Bisdom, E.B.A., Dekker, L.W., Schoute, J.F.T., 1993. Water repellency of sieve fractions from sandy soils and relationships with organic material on soil structure. Geoderma, 56, 1-4, 105-118.

Boukhoubza, F., Ait, B.A., Yacoubi-Khebiza, M., Jail, A., Hassani, L., Loukili, I.L., Nejmeddine, A., 2008. Impact of olive oil wastewater on the physicochemical and biological quality of groundwater in the Haouz plain, south of Marrakesh (Morocco). Environ. Technol., 29, 9, 959-974.

Box, J.D., 1983. Investigation of the folin-ciocalteau phenol reagent for the determination of polyphenolic substances in natural waters. Water Resources, 17, 5, 511-525.

Buchmann, C., Felten, A., Peikert, B., Muñoz, K., Bandow, N., Dag, A., Schaumann, G.E., 2015. Development of phytotoxicity and composition of a soil treated with olive mill wastewater (OMW): An incubation study. Plant Soil, $386,1,99-112$.

Chaari, L., Elloumi, N., Gargouri, K., Bourouina, B., Michichi, T., Kallel, M., 2014. Evolution of several soil properties following amendment with olive mill wastewater. Desalination and Water Treatment, 52, 10-12, 2180-2186.

Chartzoulakis, K., Psarras, G., Moutsopoulou, M., Stefanoudaki, E., 2010. Application of olive mill wastewater to a Cretan olive orchard: Effects on soil properties, plant performance and the environment. Agric., Ecosyst. Environ., 138, 3-4, 293-298.

Dan, J., Koyumdjisky, H., 1963. The soils of Israel and their distribution. J. Soil Sci., 14, 1, 12-20.

De Marco, E., Savarese, M., Paduano, A., Sacchi, R., 2007. Characterization and fractionation of phenolic compounds extracted from olive oil mill wastewaters. Food Chem., 104, 2, 858-867.

Di Bene, C., Pellegrino, E., Debolini, M., Silvestri, N., Bonari, E., 2013. Short- and long-term effects of olive mill wastewater land spreading on soil chemical and biological properties. Soil Biol. Biochem., 56, 21-30.

Di Serio, M.G., Lanza, B., Mucciarella, M.R., Russi, F., Iannucci, E., Marfisi, P., Madeo, A., 2008. Effects of olive mill wastewater spreading on the physico-chemical and microbiological characteristics of soil. Int. Biodeterior. Biodegrad., 62, 4, 403-407.

Diamantis, V., Pagorogon, L., Gazani, E., Doerr, S.H., Pliakas, F., Ritsema, C.J., 2013. Use of olive mill wastewater
(OMW) to decrease hydrophobicity in sandy soil. Ecol. Eng., 58, 393-398.

Diehl, D., Schaumann, G.E., 2007. The nature of wetting on urban soil samples: wetting kinetics and evaporation assessed from sessile drop shape. Hydrological Processes, $21,17,2255-2265$.

Doerr, S.H., Shakesby, S.H., Walsh, R.P.D., 2000. Soil water repellency: its causes, characteristics and hydrogeomorphological significance. Earth-Sci. Rev., 51, 1-4, 33-65.

Gonzalez-Vila, F.J., Verdejo, T., Delrio, J.C., Martin, F., 1995. Accumulation of hydrophobic compounds in the soil lipidic and humic fractions as result of a long-term land treatment with olive oil mill effluents (Alpechin). Chemosphere, 31, 7, 3681-3686.

Graber, E.R., Tagger, S., Wallach, R., 2009. Role of divalent fatty acid salts in soil water repellency. Soil Sci. Soc. Am. J., 73, 2, 541-549.

Hanafi, F., Belaoufi, A., Mountadar, M., Assobhei, O., 2011. Augmentation of biodegradability of olive mill wastewater by electrochemical pre-treatment: Effect on phytotoxicity and operating cost. J. Hazard. Mater., 190, 1-3, 94-99.

Hanafi, F., Mountadar, M., Etahiri, S., Fekhaoui, M., Assobhei, O., 2013. Biodegradation of toxic compounds in olive mill wastewater by a newly isolated potent strain: Aspergillus Niger van Tieghem. Journal of Water Resource and Protection, 5, 768-774.

Hanifi, S., El Hadrami, I., 2008. Phytotoxicity and fertilising potential of olive mill wastewaters for maize cultivation. Agronomy for Sustainable Development, 28, 2, 313-319.

Hanifi, S., El Hadrami, I., 2009. Olive mill wastewaters: diversity of the fatal product in olive oil industry and its valorisation as agronomical amendment of poor soils: a review. Journal of Agronomy, 8, 1, 1-13.

Hillel, D., 2003. Introduction to Environmental Soil Physics. Academic Press, San Diego, CA, USA.

Jaeger, F., Bowe, S., Schaumann, G.E., 2009. Evaluation of 1H NMR relaxometry for the assessment of pore size distribution in soil samples. Eur. J. Soil Sci., 60, 6, 10521064.

Kachouri, S., Halaouli, S., Lomascolo, A., Asther, M., Hamdi, M., 2005. Decolourization of black oxidized olive-mill wastewater by a new tannase-producing Aspergillus flavus strain isolated from soil. World J. Microbiol. Biotechnol., $21,8-9,1465-1470$.

Kavvadias, V., Doula, M.K., Komnitsas, K., Liakopoulou, N., 2010. Disposal of olive oil mill wastes in evaporation ponds: Effects on soil properties. J. Hazard. Mater., 182, 1-3, 144155.

Kurtz, M., Peikert, B., Brühl, C., Dag, A., Zipori, I., Shoqeir, J., 2015. Effects of olive mill wastewater on soil microarthropods and soil chemistry in two different cultivation scenarios in Israel and Palestinian Territories. Journal of Agriculture, 5, 857-878.

Lebron, I., Robinson, D.A., Oatham, M., Wuddivira, M.N., 2012. Soil water repellency and $\mathrm{pH}$ soil change under tropical pine plantations compared with native tropical forest. Journal of Hydrology, 414, 194-200.

Magdich, S., Ben Ahmed, C., Jarboui, R., Ben Rouina, B., Boukhris, M., Ammar, E., 2013. Dose and frequency dependent effects of olive mill wastewater treatment on the chemical and microbial properties of soil. Chemosphere, 93, 9, 1896-1903.

Mahmoud, M., Janssen, M., Haboub, N., Nassour, A., Lennartz, B., 2010. The impact of olive mill wastewater application on 
flow and transport properties in soils. Soil and Tillage Research, 107, 1, 36-41.

Meiboom, S., Gill, D., 1958. Modified spin-echo method for measuring nuclear relaxation times. Review of Scientific Instruments, 29, 688-691.

Mekki, A., Dhouib, A., Sayadi, S., 2006. Changes in microbial and soil properties following amendment with treated and untreated olive mill wastewater. Microbiol. Res., 161, 2, 93101.

Mekki, A., Dhouib, A., Sayadi, S., 2007. Polyphenols dynamics and phytotoxicity in a soil amended by olive mill wastewaters. J. Environ. Manage., 84, 2, 134-140.

Mekki, A., Dhouib, A., Sayadi, S., 2009. Evolution of several soil properties following amendment with olive mill wastewater. Progress in Natural Science, 19, 11, 1515-1521.

Meyer, M., 2015. Determination of quantitative pore size distributions of soils with $1 \mathrm{H}-\mathrm{NMR}$ relaxometry Development and validation of a universal calibration curve. Diploma Thesis, Universität Koblenz-Landau.

Moraetis, D., Stamati, F.E., Nikolaidis, N.P., Kalogerakis, N., 2011. Olive mill wastewater irrigation of maize: Impacts on soil and groundwater. Agric. Water Manage., 98, 7, 11251132.

Mulinacci, N., Romani, A., Galardi, C., Pinelli, P., Giaccherini, C., Vincieri, F.F., 2001. Polyphenolic content in olive oil waste waters and related olive samples. J. Agric. Food Chem., 49, 8, 3509-3514.

Niaounakis, M., Halvadakis, C.P., 2006. Olive Processing Waste Management Literature Review and Patent Survey. Waste Management Series, 5, 2nd ed., Elsevier Science.

Ochsner, T.E., Stephens, B.M., Koskinen, W.C., Kookana, R.S., 2006. Sorption of a hydrophilic pesticide: Effects of soil water content. Soil Sci. Soc. Am. J., 70, 6, 1991-1997.

Palestinian Central Bureau of Statistics, 2013. Statistical Yearbook of Palestine 2013, Ramallah, Palestine.

Peikert, B., 2015. Effect of olive mill wastwater on soils. PhD thesis. Universität Koblenz-Landau, Institut of Environmental Sciences.

Peikert, B., Schaumann, G.E., Keren, Y., Bukhanovsky, N., Borisover, M., Abo Garfha, M., Hassan, J., Dag, A., 2015. Characterization of topsoils subjected to poorly controlled olive oil mill wastewater pollution in West Bank and Israel. Agriculture, Ecosystems and Environment, 199, 1, 176-189.

Piotrowska, A., Iamarino, G., Rao, M.A., Gianfreda, L., 2006. Short-term effects of olive mill waste water (OMW) on chemical and biochemical properties of a semiarid Mediterranean soil. Soil Biology \& Biochemistry; 38, 600610 .
PMD, 2013. Climate Bulletin, Ministry of transport, Ramallah.

R Core Team, R, 2014. A Language and Environment for Statistical Computing. R Foundation for Statistical Computing, Vienna, Austria.

Roig, A., Cayuela, M.L., Sanchez-Monedero, M.A., 2006. An overview on olive mill wastes and their valorisation methods. Waste Manage., 26, 9, 960-969.

Saadi, I., Laor, Y., Raviv, M., Medina, S., 2007a. Effect of the olive oil wastewater application on microbial activity and phytotoxicity in soil. Alon Hanotea, 61, 453-455.

Saadi, I., Laor, Y., Raviv, M., Medina, S., 2007b. Land spreading of olive mill wastewater: Effects on soil microbial activity and potential phytotoxicity. Chemosphere, 66, 1, 75-83.

Saviozzi, A., Levi-Minzi, R., Riffaldi, R., Lupetti, A., 1991. Effetti dello spandimento di acque di vegetazione sul terreno agrario. Agrochimica, 35, 135-148.

Sierra, J., Marti, E., Montserrat, G., Cruanas, R., Garau, M.A., 2001. Characterisation and evolution of a soil affected by olive oil mill wastewater disposal. Sci. Total Environ., 279, 1-3, 207-214.

Sierra, J., Marti, E., Garau, M.A., Cruanas, R., 2007. Effects of the agronomic use of olive oil mill wastewater: Field experiment. Sci. Total Environ., 378, 1-2, 90-94.

Sobhi, B., Isam, S., Ahmad, Y., Jacob, H., 2008. Reducing the environmental impact of olive mill wastewater in Jordan, Palestine and Israel. In: Shuval, H., Dweik, H. (Eds.): Water Resources in the Middle East, Springer, pp. 409-415.

Spandre, R., Dellomonaco, G., 1996. Polyphenols pollution by olive mill waste waters. Journal of Environmental Hydrology, 4, 1-13.

Steinmetz, Z., Kurtz, M.P., Dag, A., Zipori, I., Schaumann, G.E., 2015. The seasonal influence of olive mill wastewater applications on an orchard soil under semi-arid conditions. J. Plant Nutr. Soil Sci., 178, 641-648.

Täumer, K., Stoffregen, H., Wessolek, G., 2005. Determination of repellency distribution using soil organic matter and water content. Geoderma, 125, 1-2, 107-115.

Tsiknia, M., Tzanakakis, V.A., Oikonomidis, D., Paranychianakis, N.V., Nikolaidis, N.P., 2014. Effects of olive mill wastewater on soil carbon and nitrogen cycling. Appl. Microbiol. Biotechnol., 98, 6, 2739-2749.

Zenjari, B., Nejmeddine, A., 2001. Impact of spreading olive mill wastewater on soil characteristics: laboratory experiments. Agronomie, 21, 749-755.

Received 4 September 2015 Accepted 1 February 2016 


\section{SUPPLEMENTARY MATERIAL}

\section{The proton balance}

In order to determine the proton balance, i.e., the amount of protons or hydroxyl ions needed to increase or decrease the $\mathrm{pH}$ of the control samples, one pooled soil sample (from all control plots) was extracted $(1: 5 \mathrm{wt} / \mathrm{vol})$ with aqueous solutions of different concentrations of $\mathrm{NaOH}$ and $\mathrm{HCl}$. The $\mathrm{pH}$ was recorded after horizontal shaking for 2, 24 and $48 \mathrm{~h}$ and plotted vs. the molar concentration in mol kg-1 of base or acid supplied. The result of this plot is an "S" shaped curve (Fig. S1).

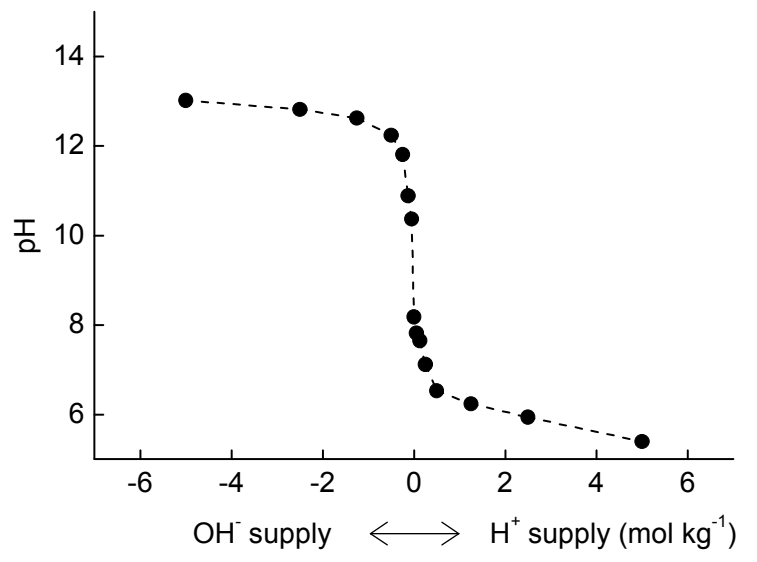

Fig. S1. $\mathrm{pH}$ titration curve of one pooled soil sample (from all control plots). Within the $\mathrm{pH}$-range of all samples, we defined two regions which could be fitted linearly (Figure S2) with the slope $a$ and the intercept $b$.

\section{Figures}

(a)

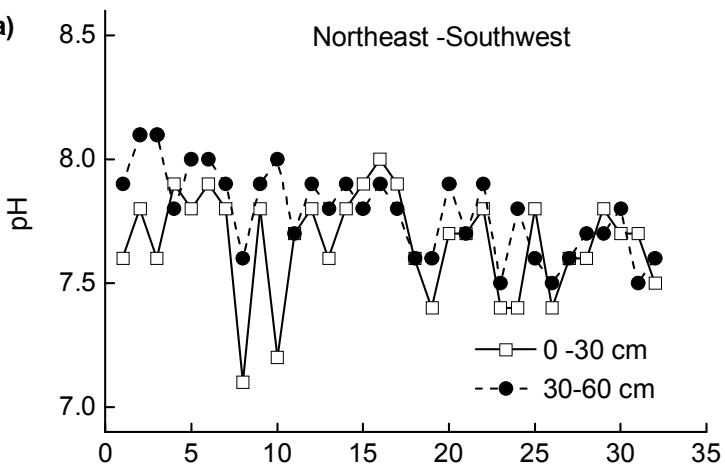

(c)

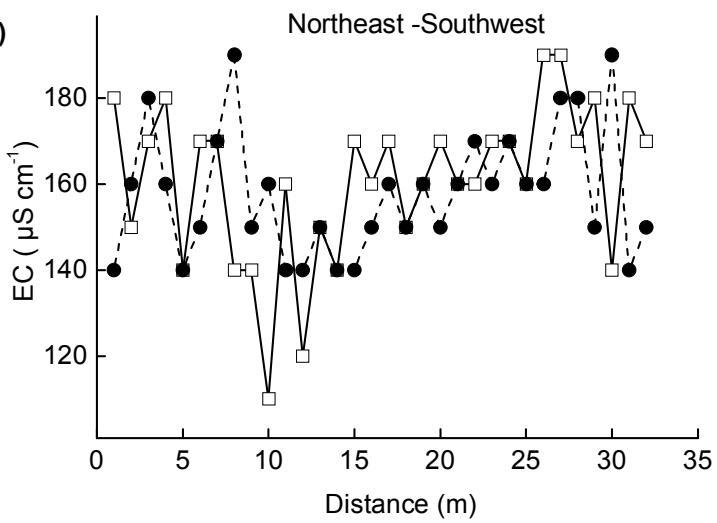

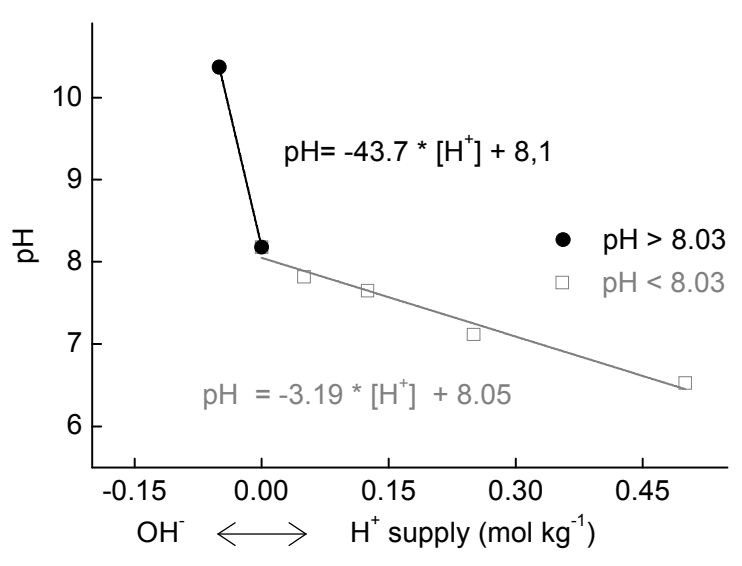

Fig. S2. Linear fitting for $\mathrm{pH}$ range (6 to 11). With the help of these linear functions, we calculated $\left[\mathrm{H}^{+}\right]$concentration from $\mathrm{pH}$ of the sample using Eq. (A.1) and (A.2).

$$
\begin{aligned}
& {\left[\mathrm{H}^{+}\right]_{\mathrm{OMW}}=\frac{\mathrm{pH}_{\mathrm{OMW}}-b}{a}} \\
& {\left[\mathrm{H}^{+}\right]_{\text {control }}=\frac{\mathrm{pH}_{\text {control }}-b}{a}}
\end{aligned}
$$

The $\mathrm{H}^{+}$supply by OMW treatment $\left(\Delta\left[\mathrm{H}^{+}\right]\right)$was calculated by the difference in $\left[\mathrm{H}^{+}\right]$between treated and respective control samples (Eq. A.3)

$$
\Delta\left[\mathrm{H}^{+}\right]=\left[\mathrm{H}^{+}\right]_{\text {control }}-\left[\mathrm{H}^{+}\right]_{\mathrm{OMW}}
$$
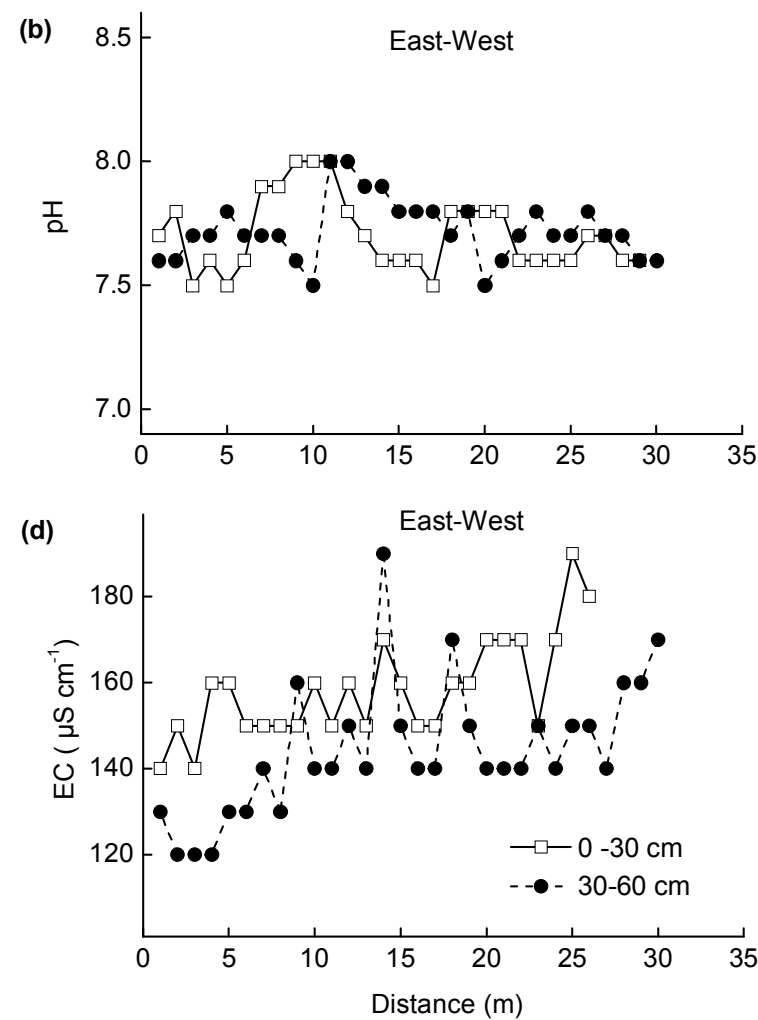

Fig. S3. Spatial distribution of (a) $\mathrm{pH}$ in Southwest-Northeast transect, (b) $\mathrm{pH}$ in East- West transect, (c) Electrical conductivity (EC) Southwest-Northeast transect and (d) EC in East-West transect obtained for site exploration in July 2011 (see Fig. 1). 


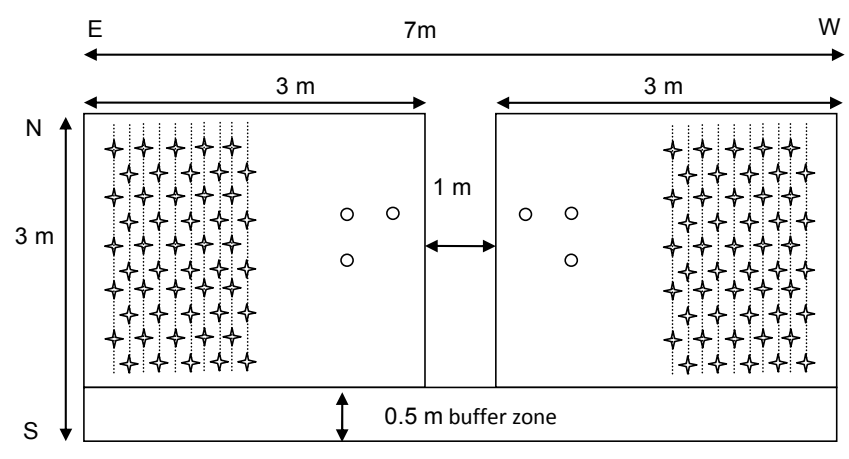

○

Moisture tubes

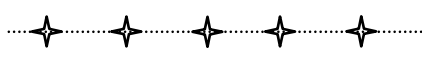

(Each line represents one sampling event)

Fig. S4. Overview of each two parallel plots located in the field and the sampling points for each event after olive mill waste water (OMW) application to soil.

(a) Hydraulic potential gradient $(\mathrm{hPa})$ $-8 \times 10^{5}-6 \times 10^{5}-4 \times 10^{5}-2 \times 10^{5} \quad 0 \quad 2 \times 10^{5}$

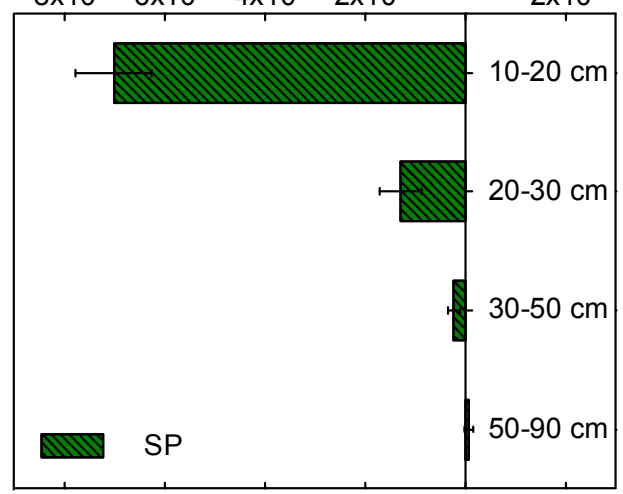

(c) Hydraulic potential gradient $(\mathrm{hPa})$

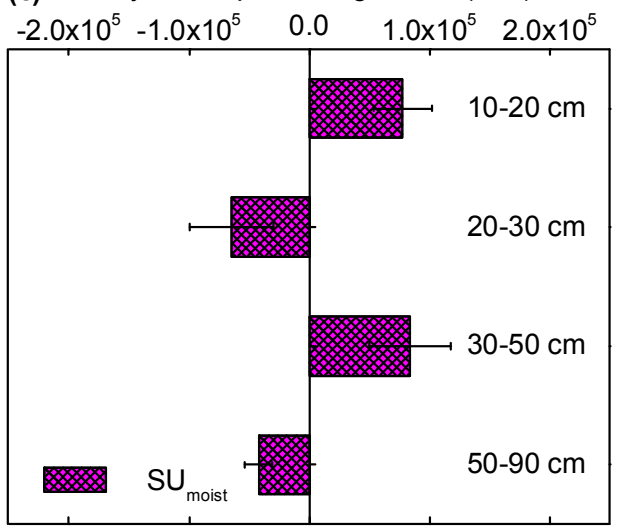

Hydraulic potential gradient $(\mathrm{hPa})$

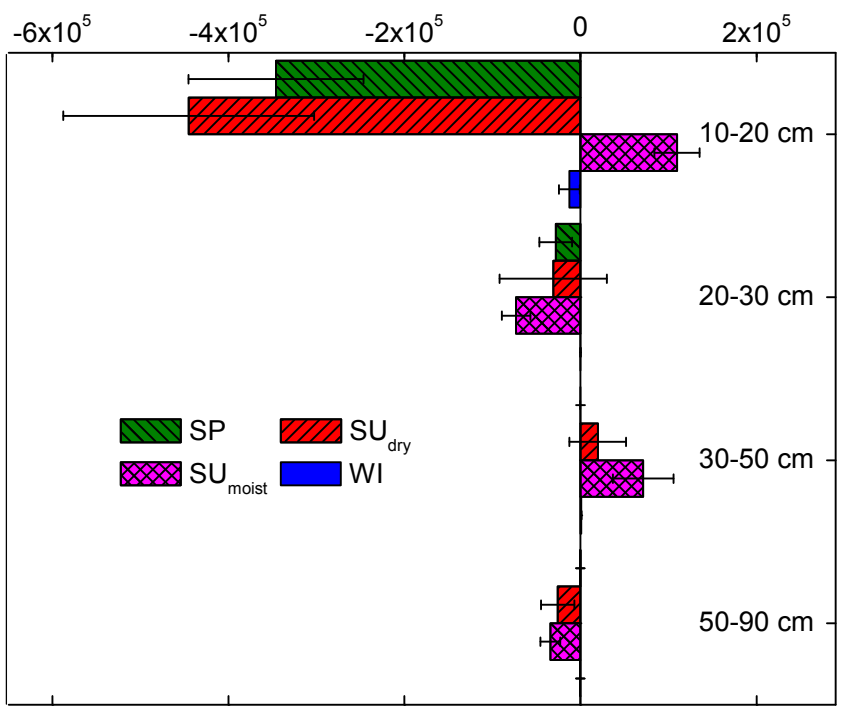

Fig. S5. Average of estimated hydraulic potential gradient as a function of soil depth for spring (SP), summer without irrigation $\left(\mathrm{SU}_{\mathrm{dry}}\right)$, summer with irrigation $\left(\mathrm{SU}_{\text {moist }}\right)$, and winter $(\mathrm{WI})$ treatment plots one week prior to olive mill waste water (OMW) application. Data points are mean of six values of two treated plots for each treatment with error bars representing standard errors.

(b) Hydraulic potential gradient $(\mathrm{hPa})$

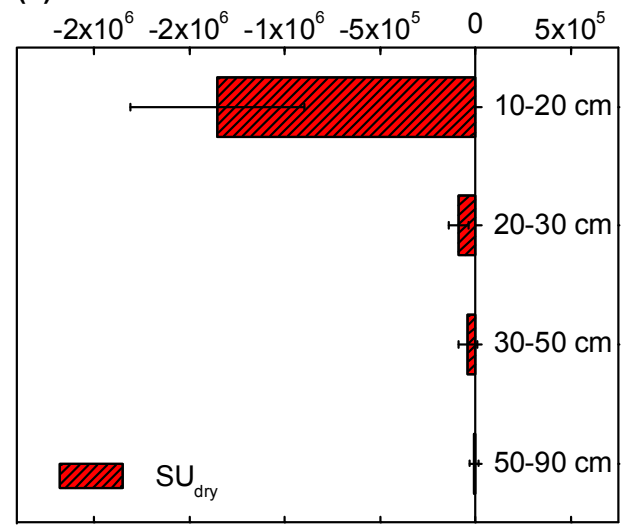

(d) Hydraulic potential gradient $(\mathrm{hPa})$

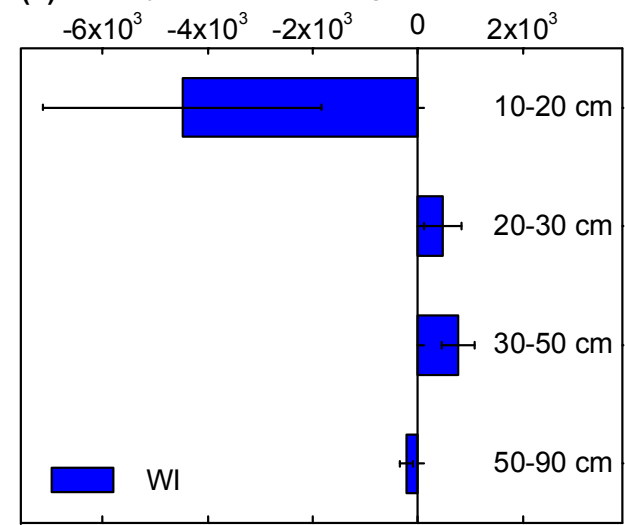

Fig. S6. Average of estimated hydraulic potential gradient as a function of soil depth for (a) spring (SP), (b) summer without irrigation $\left(\mathrm{SU}_{\mathrm{dry}}\right)$, (c) summer with irrigation $\left(\mathrm{SU}_{\text {moist }}\right)$ during the summer season 2012 and for (d) winter (WI) treatment plots during the winter season 2012/13. Data points are means of six values of two treated plots for each treatment with error bars representing standard errors. 


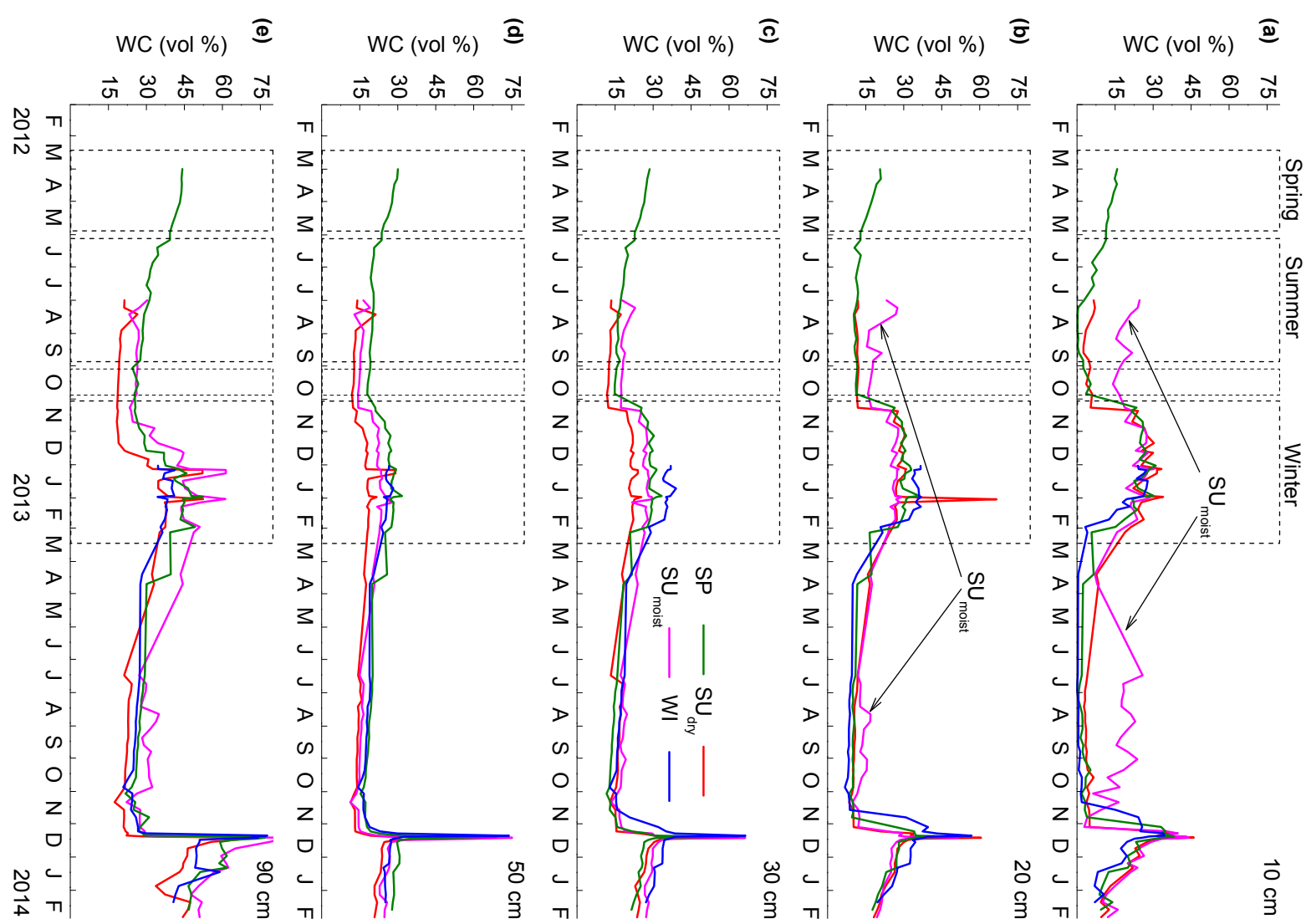

Fig. S7. Average of weekly measurements of soil water content in field (vol. \%) in (a) $10 \mathrm{~cm}$, (b) $20 \mathrm{~cm}$, (c) $30 \mathrm{~cm}$, (d) $50 \mathrm{~cm},($ e) $90 \mathrm{~cm}$ depth for spring $(\mathrm{SP})$, summer without irrigation $\left(\mathrm{SU}_{\mathrm{dry}}\right)$, summer with irrigation $\left(\mathrm{SU}_{\text {moist }}\right)$, and winter $(\mathrm{WI})$ treatment plots as a function of time. Data points are means of six values of two treated plots for each treatment with a standard deviation of 5\%.

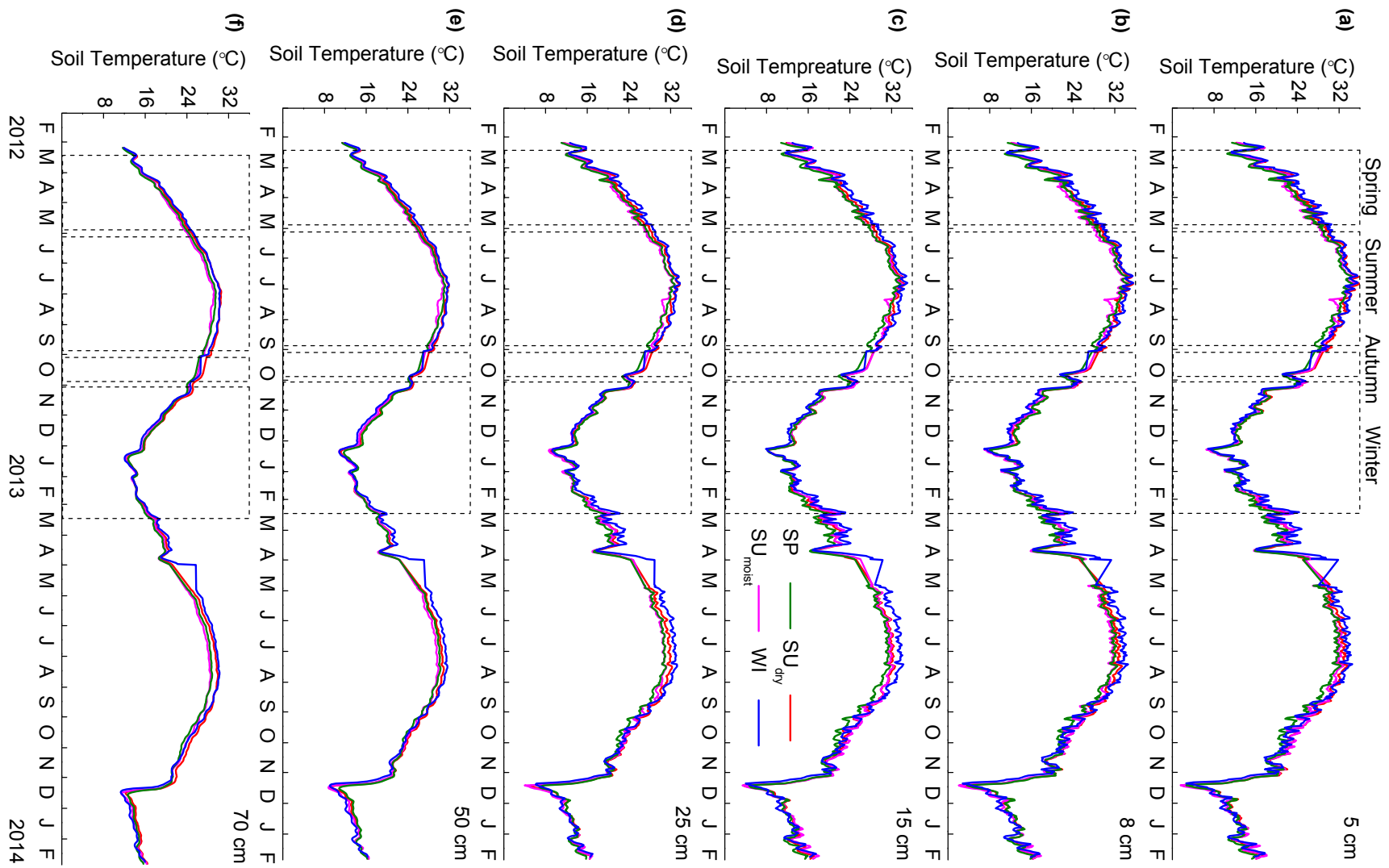

Fig. S8. Daily average of soil temperature $\left({ }^{\circ} \mathrm{C}\right)$ in (a) $5 \mathrm{~cm}$, (b) $8 \mathrm{~cm},(\mathbf{c}) 15 \mathrm{~cm}$, (d) $25 \mathrm{~cm}$, (e) $50 \mathrm{~cm}$, (f) $70 \mathrm{~cm}$ depth for spring (SP), summer without irrigation $\left(\mathrm{SU}_{\mathrm{dry}}\right)$, summer with irrigation $\left(\mathrm{SU}_{\text {moist }}\right)$, and winter $(\mathrm{WI})$ treatment plots as a function of time. Data points are means of hourly measurements over $24 \mathrm{~h}$ for one probe for each treatment. 


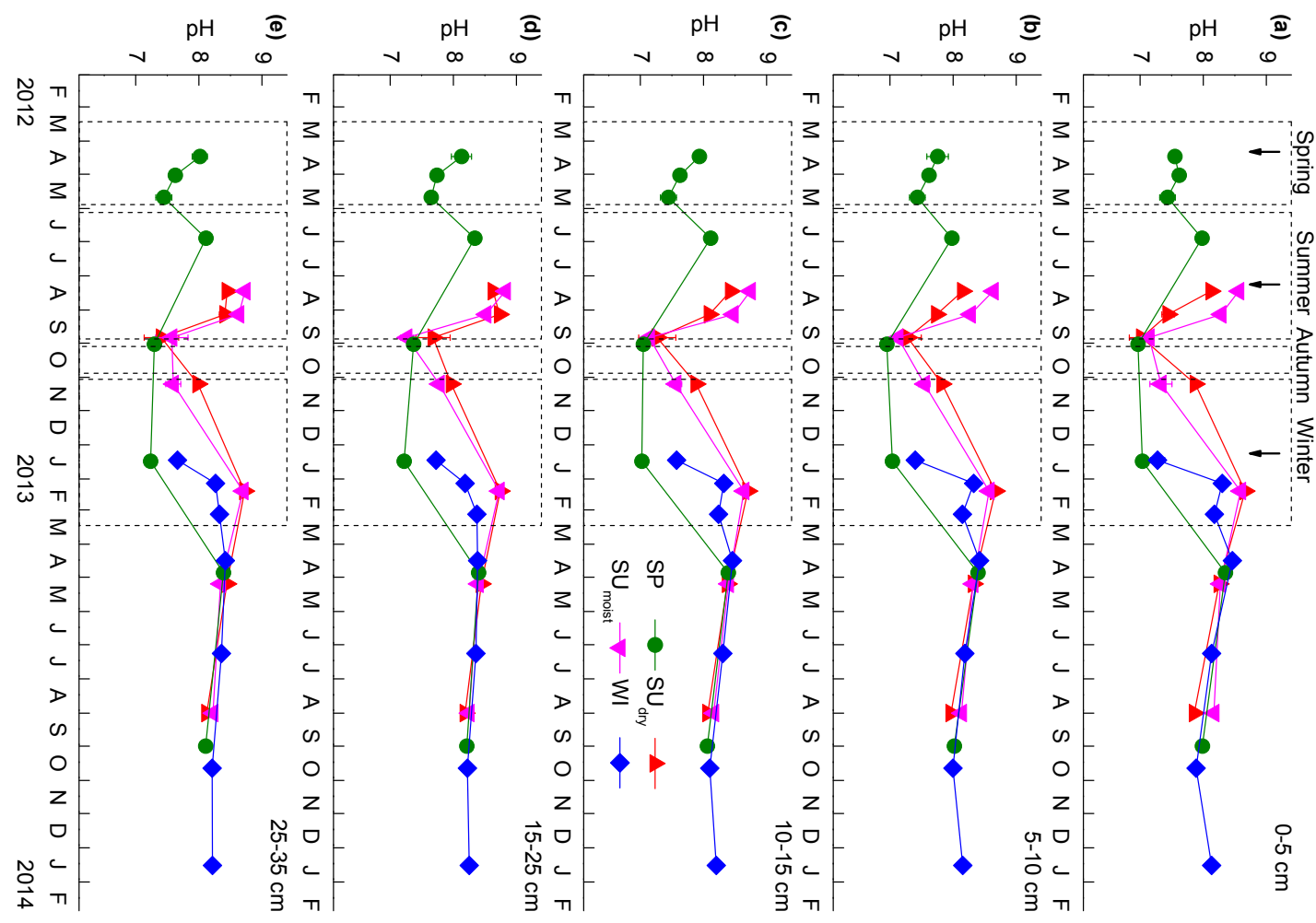

Fig. S9. Average of $\mathrm{pH}$ of olive mill waste water (OMW) treated plots in (a) 0-5 cm, (b) 5-10 cm, (c) 10-15 cm, (d) $15-25 \mathrm{~cm}$ and (e) $25-$ $35 \mathrm{~cm}$ depth for spring (SP), summer without irrigation $\left(\mathrm{SU}_{\mathrm{dry}}\right)$, summer with irrigation $\left(\mathrm{SU}_{\text {moist }}\right)$, and winter (WI) application as a function of time. First results obtained 2 days after OMW application to soil $(\downarrow)$. Data points are means of six values of two plots for each treatment with error bars representing standard errors.

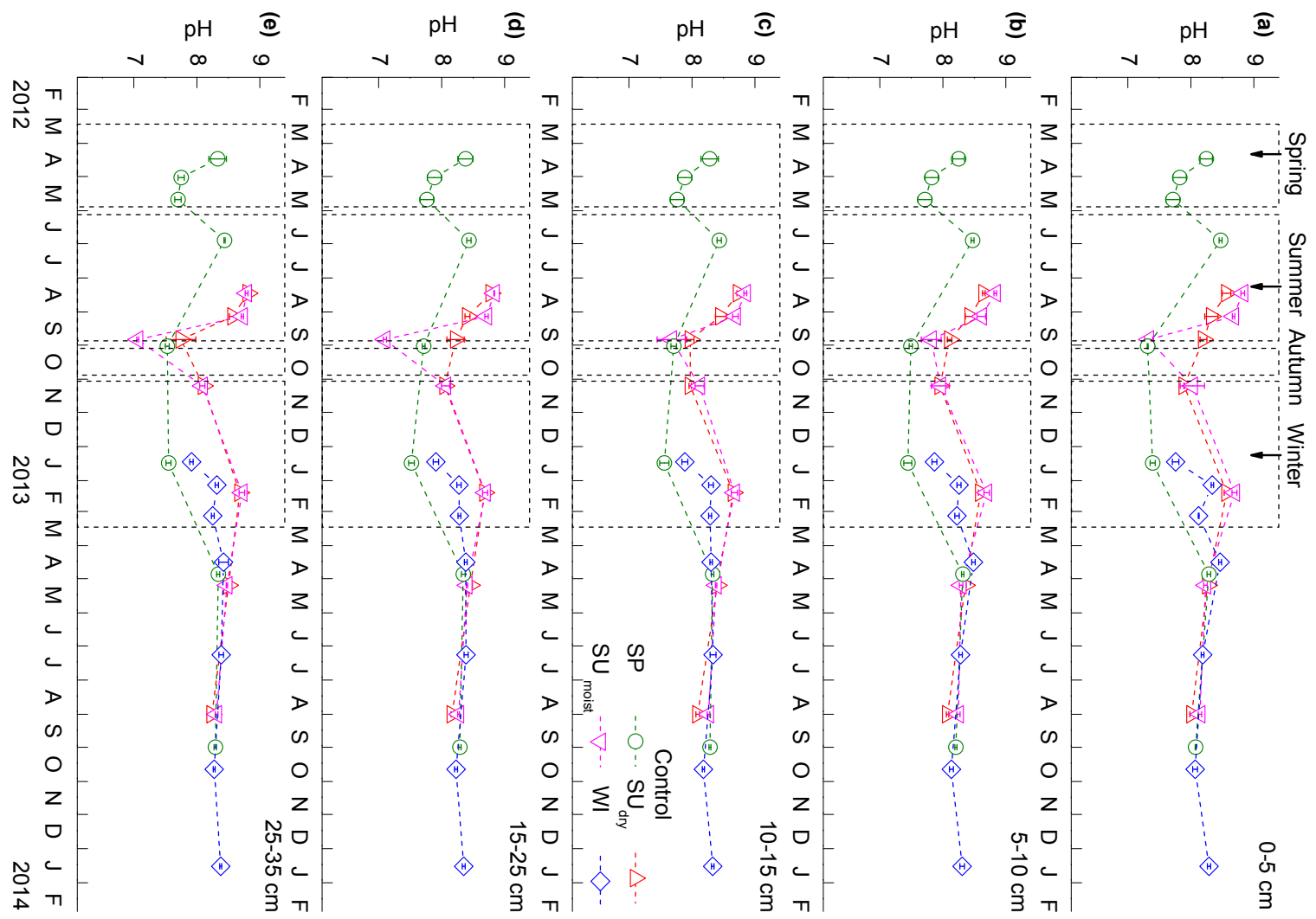

Fig. S10. Average of pH of control plots in (a) 0-5 cm, (b) 5-10 cm, (c) 10-15 cm, (d) $15-25 \mathrm{~cm}$ and (e) $25-35 \mathrm{~cm}$ depth for spring (SP), summer without irrigation $\left(\mathrm{SU}_{\mathrm{dry}}\right)$, summer with irrigation $\left(\mathrm{SU}_{\text {moist }}\right)$, and winter $(\mathrm{WI})$ application as a function of time. First results obtained 2 days after tap water application to soil $(\downarrow)$. Data points are means of six values of two plots for each control with error bars representing standard errors. 


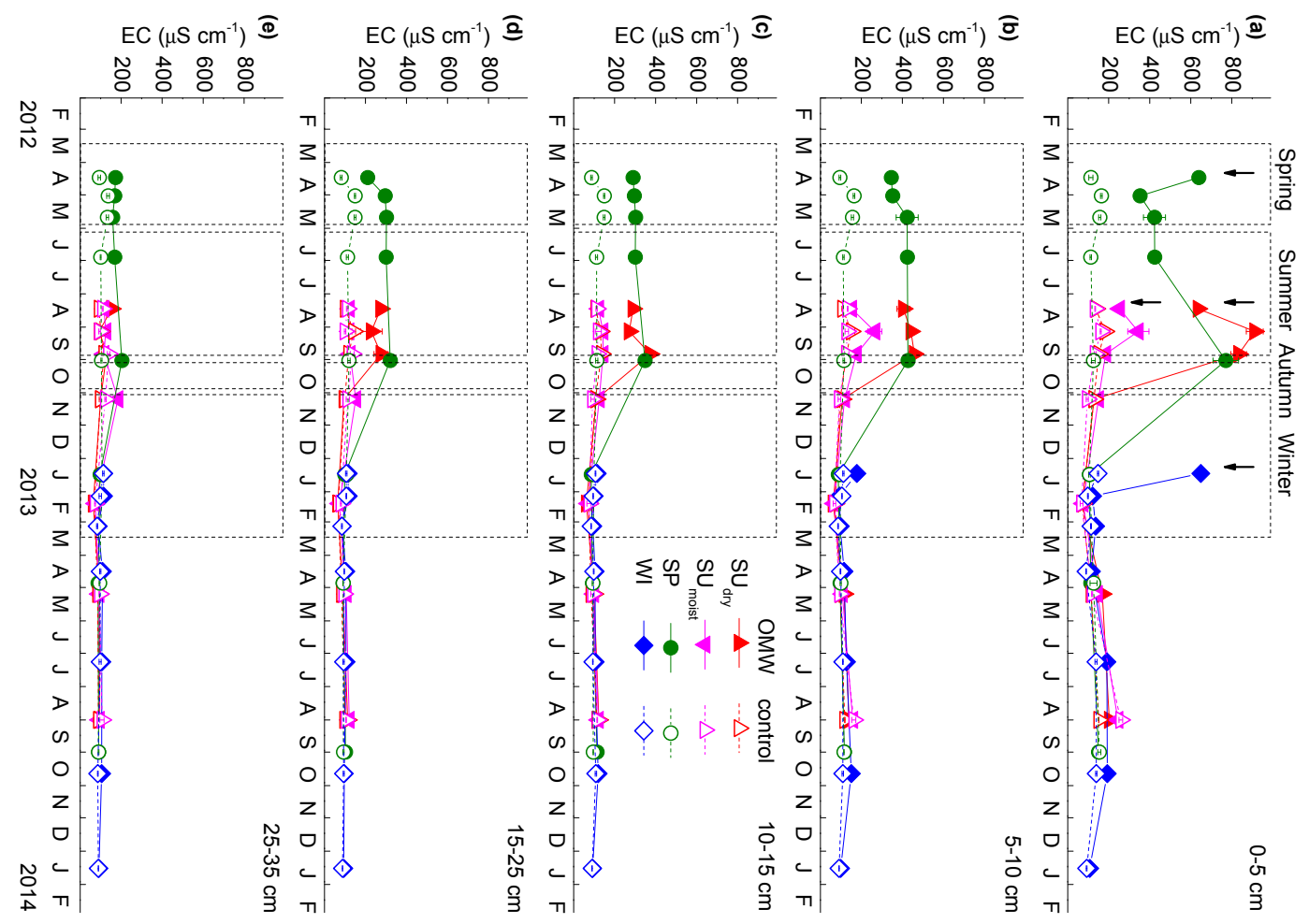

Fig. S11. Average of electrical conductivity (EC) in (a) $0-5 \mathrm{~cm}$, (b) $5-10 \mathrm{~cm}$, (c) $10-15 \mathrm{~cm}$, (d) $15-25 \mathrm{~cm}$ and (e) $25-35 \mathrm{~cm}$ depth for spring $(\mathrm{SP})$, summer without irrigation $\left(\mathrm{SU}_{\mathrm{dry}}\right)$, summer with irrigation $\left(\mathrm{SU}_{\text {moist }}\right)$, and winter $(\mathrm{WI})$ olive mill waste water $(\mathrm{OMW})$ treated and the respective control plots as a function of time. First results obtained 2 days after application to soil ( $\downarrow$ ). Data points are means of six values of two plots for each treatment and two plots for each control with error bars representing standard errors.

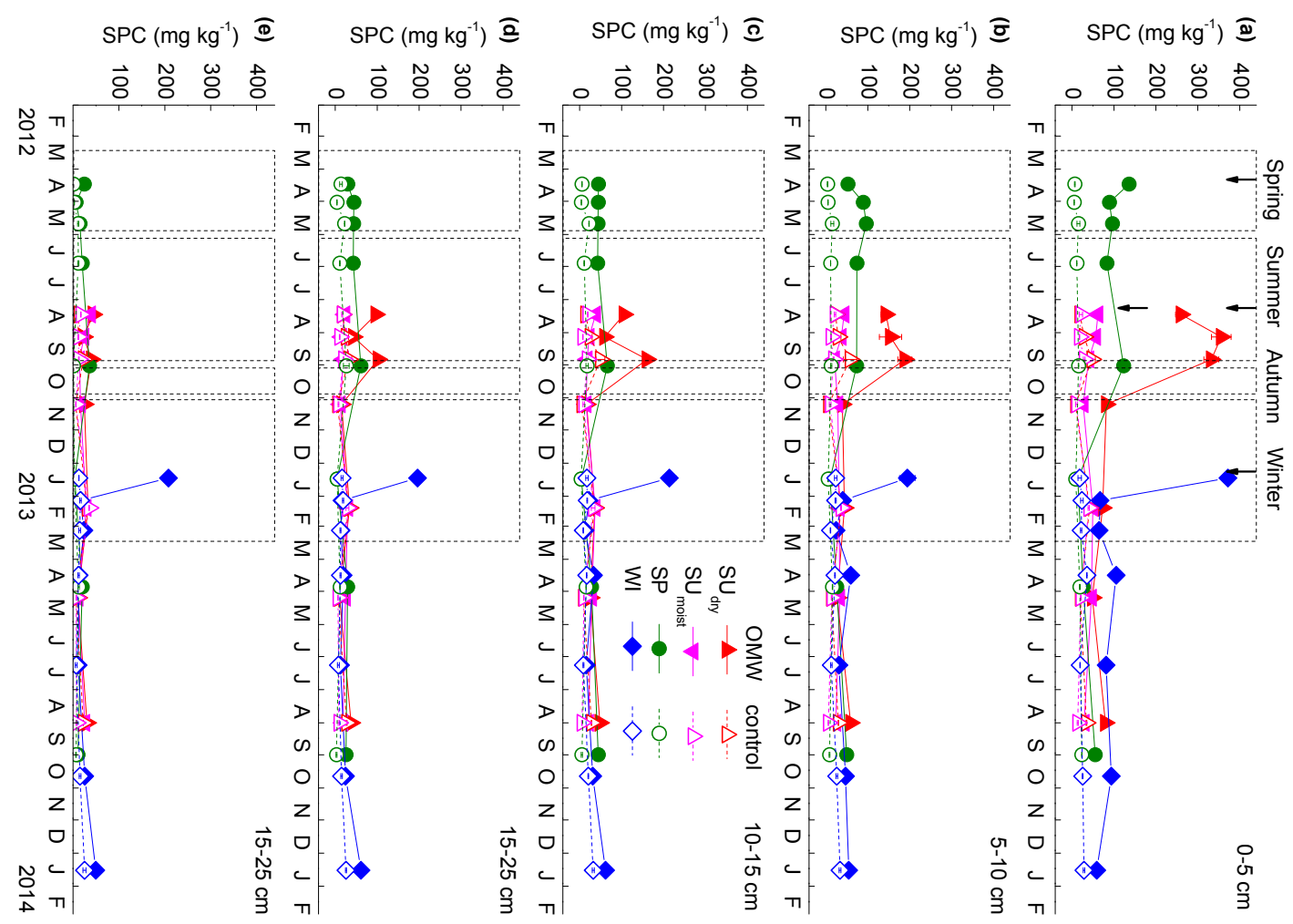

Fig. S12. Average of soluble phenolic compounds content $(S P C)$ in (a) $0-5 \mathrm{~cm}$, (b) 5-10 cm, (c) 10-15 cm, (d) $15-25 \mathrm{~cm}$ and (e) $25-$ $35 \mathrm{~cm}$ depth for spring (SP), summer without irrigation $\left(\mathrm{SU}_{\mathrm{dry}}\right)$, summer with irrigation $\left(\mathrm{SU}_{\text {moist }}\right)$, and winter (WI) olive mill waste water (OMW) treated and the respective control plots as a function of time. First results obtained 2 days after OMW application to soil ( $\downarrow$ ). Data points are means of six values of two plots for each treatment and two plots for each control with error bars representing standard errors. 


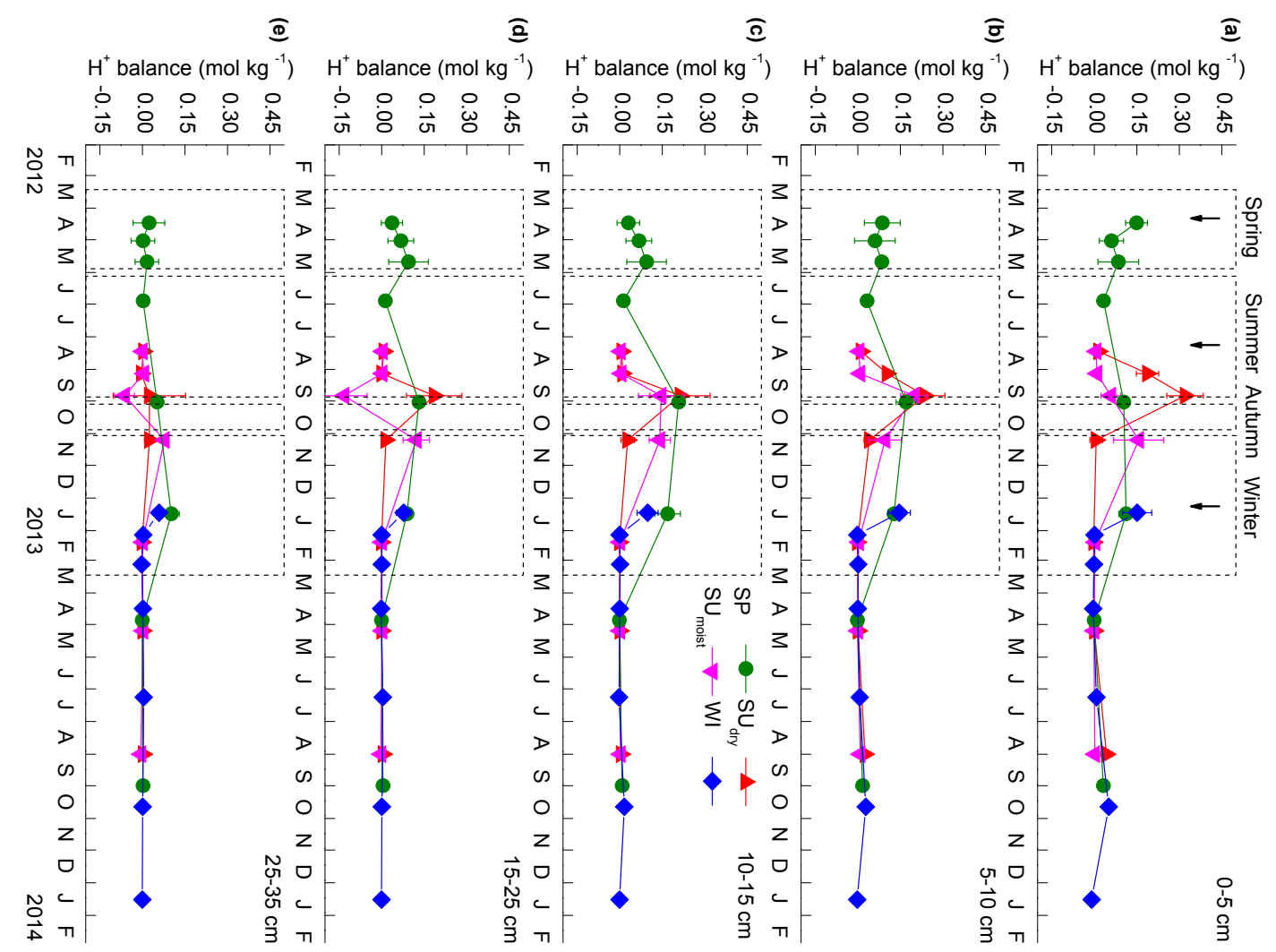

Fig. S13. Average of $\mathrm{H}^{+}$balance (see text for explanation) (a) 0-5 cm, (b) 5-10 cm, (c) $10-15 \mathrm{~cm}$, (d) $15-25 \mathrm{~cm}$ and (e) $25-35 \mathrm{~cm}$ depth for spring $(\mathrm{SP})$, summer without irrigation $\left(\mathrm{SU}_{\mathrm{dry}}\right)$, summer with irrigation $\left(\mathrm{SU}_{\text {moist }}\right)$, and winter $(\mathrm{WI})$ treatment plots and the control plots as a function of time. Data points are means of six values of two plots for each treatment with error bars representing standard errors.

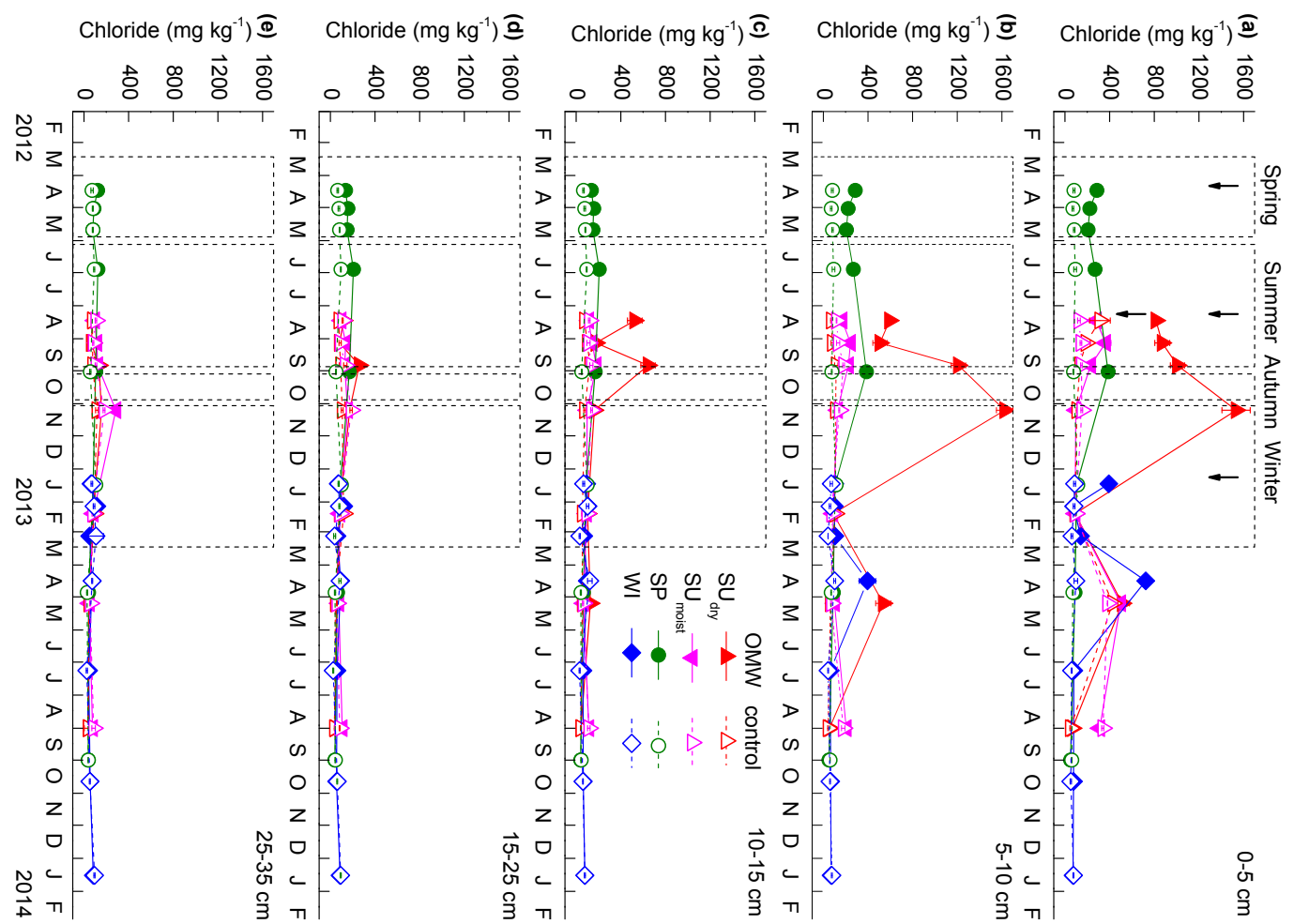

Fig. S14. Average of chloride ion concentration $(\mathrm{Cl}\urcorner$ in (a) $0-5 \mathrm{~cm}$, (b) $5-10 \mathrm{~cm}$, (c) $10-15 \mathrm{~cm}$, (d) $15-25 \mathrm{~cm}$ and (e) $25-35 \mathrm{~cm}$ depth for spring (SP), summer without irrigation $\left(\mathrm{SU}_{\mathrm{dry}}\right)$, summer with irrigation $\left(\mathrm{SU}_{\text {moist }}\right)$, and winter $(\mathrm{WI})$ treatment plots and the control plots as a function of time. First results obtained 2 days after OMW application to soil $(\downarrow)$. Data points are means of six values of two plots for each treatment and two plots for each control with error bars representing standard errors. 
Tables

Table S1. Overview of soil samples and the obtained parameter as well as the monitoring data during the field experiment.

\begin{tabular}{|c|c|c|c|c|c|}
\hline \multicolumn{6}{|c|}{ Soil samples and obtained parameters } \\
\hline \multicolumn{2}{|c|}{ Treatment } & No. of plots & Sampling time & Sampling depth & Parameters \\
\hline \multicolumn{2}{|c|}{4 treatments } & $\begin{array}{c}4 \text { plots for } \\
\text { each treatment }\end{array}$ & $\begin{array}{l}8 \text { time points } \\
\text { for each plot }\end{array}$ & $\begin{array}{l}5 \text { depth }(\mathrm{cm}) \\
\text { for each time }\end{array}$ & $\begin{array}{l}640 \text { samples } \\
\text { (3 repl. each) }\end{array}$ \\
\hline \multirow[t]{2}{*}{ SP } & Spring & & 1 week before & & \\
\hline & 2012-04-12 & & 2 days after & $0-5$ & $W C$ (grav.) \\
\hline \multirow{2}{*}{$\mathrm{SU}_{\text {dry }}$} & Summer (dry) & 2 OMW & 3 weeks after & $5-10$ & $\mathrm{pH}$ \\
\hline & $2012-08-13$ & 2 control & 6 weeks after & $10-15$ & $E C$ \\
\hline \multirow{2}{*}{$\mathrm{SU}_{\text {moist }}$} & Summer (moist) & & 3 months after & $15-25$ & $\mathrm{Cl}$ \\
\hline & $2012-08-13$ & & 6 months after & $25-35$ & $S P C$ \\
\hline \multirow[t]{2}{*}{ WI } & Winter & & 9 months after & & $W D P T$ \\
\hline & 2013-01-14 & & $\begin{array}{c}\text { 12-18 months after } \\
\text { treatment }\end{array}$ & & \\
\hline \multicolumn{6}{|c|}{ Monitoring data } \\
\hline \multicolumn{2}{|c|}{ Parameter } & Method & No. of probes & depth / height $\mathrm{m}$ & Frequency \\
\hline \multicolumn{2}{|c|}{ Air temperature } & & & & \\
\hline \multicolumn{2}{|c|}{$\begin{array}{l}\text { Air humidity } \\
\text { Precipitation }\end{array}$} & $\begin{array}{l}\text { Meteorological } \\
\text { station }\end{array}$ & 1 & $2 \mathrm{~m}$ above ground & hourly \\
\hline \multicolumn{2}{|c|}{ Soil temperature } & Temperature sensors & 8 & $\begin{array}{c}5 \text { depths } \\
5,8,15,50,70 \mathrm{~cm}\end{array}$ & hourly \\
\hline \multicolumn{2}{|c|}{$\begin{array}{l}\text { Volumetric soil } \\
\text { moisture }\end{array}$} & Moisture probes & 48 & $\begin{array}{c}5 \text { depths: } \\
10,20,30,50,90 \mathrm{~cm}\end{array}$ & weekly \\
\hline
\end{tabular}

Table S2. Results of Wilcoxon rank sum test of data of the plots treated with olive mill waste water (OMW) in spring (SP), summer without irrigation $\left(\mathrm{SU}_{\mathrm{dry}}\right)$, summer with irrigation $\left(\mathrm{SU}_{\text {moist }}\right)$, and winter $(\mathrm{WI})$ against the respective control plots 2 days after OMW application (short-term effects). Listed are $p$-values (shaded in light red for $p<0.05$ and dark red for $p<0.01$ ) for each depth for the parameters $\mathrm{pH}$ and electrical conductivity $(E C)$, soluble phenolic compounds $(S P C)$ and chloride $(\mathrm{Cl})$.

\begin{tabular}{|c|c|c|c|c|c|c|}
\hline depth & $(\mathrm{cm})$ & $0-5$ & $5-10$ & $10-15$ & $15-25$ & $25-35$ \\
\hline \multicolumn{7}{|c|}{$\mathrm{pH}$} \\
\hline SP & 2 days & 0.005 & 0.0247 & 0.132 & 0.1797 & 0.1712 \\
\hline $\mathrm{SU}_{\mathrm{dry}}$ & 2 days & 0.0022 & 0.0022 & 0.0022 & 0.0022 & 0.0064 \\
\hline $\mathrm{SU}_{\text {moist }}$ & 2 days & 0.0022 & 0.005 & 0.0646 & 0.0022 & 0.4848 \\
\hline WI & 2 days & 0.005 & 0.0022 & 0.0101 & 0.0124 & 0.0081 \\
\hline \multicolumn{7}{|c|}{$E C$} \\
\hline SP & 2 days & 0.005 & 0.0022 & 0.0022 & 0.0022 & 0.0022 \\
\hline $\mathrm{SU}_{\text {dry }}$ & 2 days & 0.0022 & 0.0022 & 0.005 & 0.0022 & 0.0022 \\
\hline $\mathrm{SU}_{\text {moist }}$ & 2 days & 0.005 & 0.005 & 0.0048 & 0.8182 & 0.0651 \\
\hline WI & 2 days & 0.005 & 0.0022 & 0.01 & 0.1986 & 0.6304 \\
\hline \multicolumn{7}{|c|}{$S P C$} \\
\hline SP & 2 days & 0.005 & 0.0022 & 0.0049 & 0.0022 & 0.005 \\
\hline $\mathrm{SU}_{\mathrm{dry}}$ & 2 days & 0.0022 & 0.0022 & 0.005 & 0.0049 & 0.005 \\
\hline $\mathrm{SU}_{\text {moist }}$ & 2 days & 0.005 & 0.005 & 0.005 & 0.0298 & 0.005 \\
\hline WI & 2 days & 0.0022 & 0.0022 & 0.0022 & 0.0022 & 0.005 \\
\hline \multicolumn{7}{|c|}{$\mathrm{Cl}$} \\
\hline SP & 2 days & 0.005 & 0.0048 & 0.0046 & 0.008 & 0.0423 \\
\hline $\mathrm{SU}_{\mathrm{dry}}$ & 2 days & 0.0043 & 0.0043 & 0.0048 & 0.0048 & 0.0043 \\
\hline $\mathrm{SU}_{\text {moist }}$ & 2 days & 0.0049 & 0.0046 & 0.9354 & 0.3726 & 0.37 \\
\hline WI & 2 days & 0.0049 & 0.1269 & 0.0126 & 0.8089 & 0.0916 \\
\hline
\end{tabular}


Effects of olive mill wastewater disposal on soil: Interaction mechanisms during different seasons

Table S3. Results of Wilcoxon rank sum test of data of the plots treated with olive mill waste water (OMW) in spring (SP), summer without irrigation $\left(\mathrm{SU}_{\mathrm{dry}}\right)$, summer with irrigation $\left(\mathrm{SU}_{\text {moist }}\right)$, and winter $(\mathrm{WI})$. Listed are $p$-values (shaded in red for values $\left.<0.05\right)$ to test significant changes during spring, summer and winter 2012 and summer 2013 (long-term effects) for each depth for the parameters $\mathrm{pH}$, electrical conductivity $(E C)$ and soluble phenolic compounds $(S P C)$. Water drop penetration time (WDPT) data are obtained in field only for the top layer.

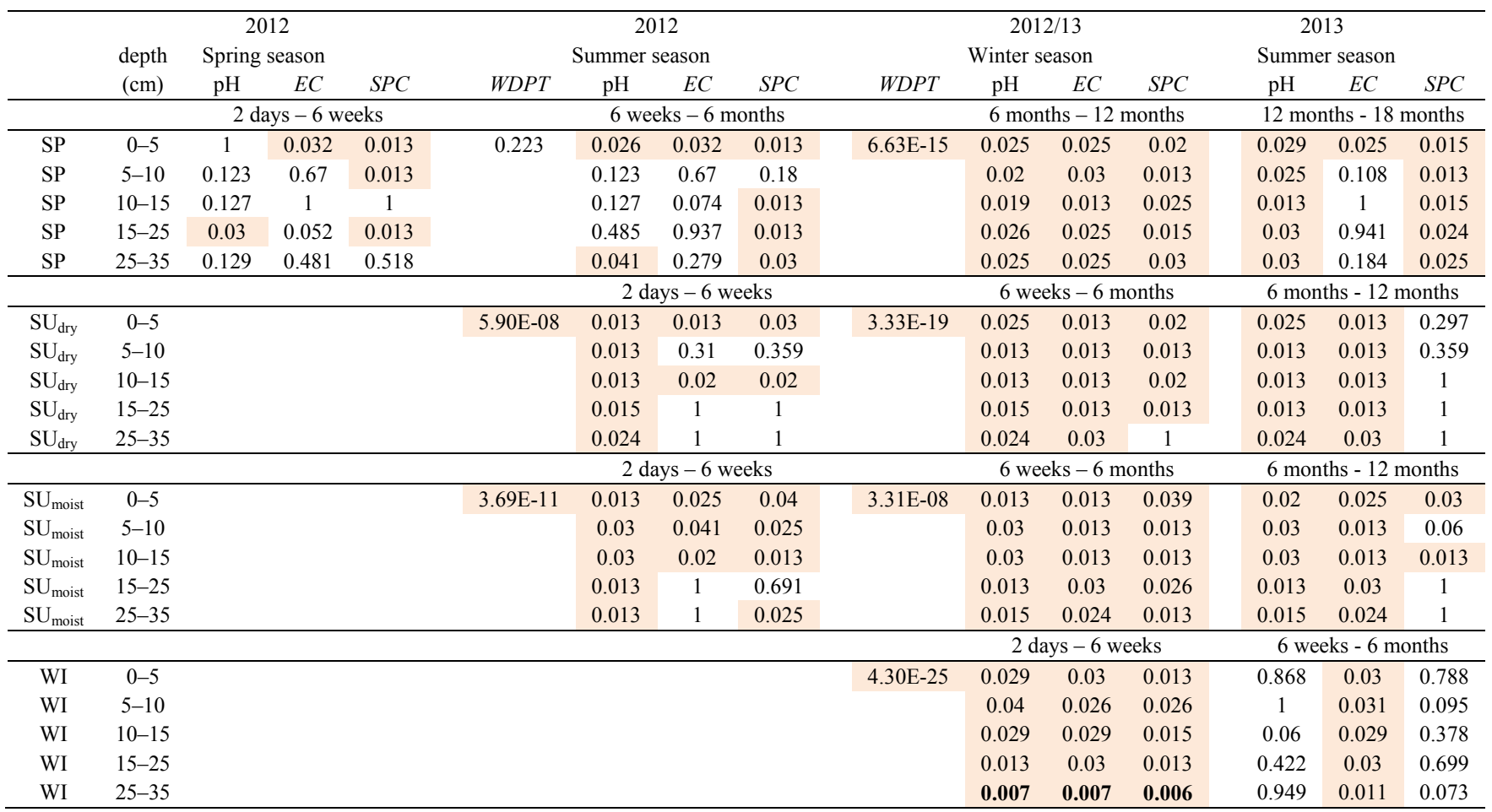

Table S4. Results of Wilcoxon rank sum test of data of the plots treated with olive mill waste water (OMW) in spring (SP), summer without irrigation $\left(\mathrm{SU}_{\mathrm{dry}}\right)$, summer with irrigation $\left(\mathrm{SU}_{\text {moist }}\right)$, and winter $(\mathrm{WI})$ against the respective control plots at different time points after the application (long-term effects). Listed are $p$-values (shaded in red for $p<0.05$, in dark red for $p<0.01$ ) for each depth and for the parameters $\mathrm{pH}$, electrical conductivity $(E C)$ and soluble phenolic compounds $(S P C)$.

\begin{tabular}{|c|c|c|c|c|c|c|c|c|c|c|}
\hline & \multirow{2}{*}{$\begin{array}{c}\text { depth } \\
(\mathrm{cm})\end{array}$} & \multicolumn{3}{|c|}{2013} & \multicolumn{3}{|c|}{2013} & \multicolumn{3}{|c|}{$2013 / 14$} \\
\hline & & $\mathrm{pH}$ & $E C$ & $S P C$ & $\mathrm{pH}$ & $E C$ & $S P C$ & $\mathrm{pH}$ & $E C$ & $S P C$ \\
\hline & & \multicolumn{3}{|c|}{12 months } & \multicolumn{3}{|c|}{18 months } & & & \\
\hline SP & $0-5$ & 0.8089 & 0.810 & 0.010 & 0.072 & 0.310 & 0.005 & & & \\
\hline SP & $5-10$ & 0.1087 & 0.575 & 0.005 & 0.005 & 1.000 & 0.002 & & & \\
\hline SP & $10-15$ & 0.0771 & 0.935 & 0.005 & 0.005 & 1.000 & 0.002 & & & \\
\hline SP & $15-25$ & 0.2607 & 0.685 & 0.005 & 0.005 & 0.394 & 0.005 & & & \\
\hline \multirow[t]{2}{*}{ SP } & $25-35$ & 0.1994 & 0.029 & 0.005 & 0.010 & 0.810 & 0.025 & & & \\
\hline & & \multicolumn{3}{|c|}{9 months } & \multicolumn{3}{|c|}{12 months } & & & \\
\hline $\mathrm{SU}_{\mathrm{dry}}$ & $0-5$ & 0.686 & 0.002 & 0.005 & 0.020 & 0.005 & 0.002 & & & \\
\hline$S U_{\text {dry }}$ & $5-10$ & 0.295 & 0.013 & 0.026 & 0.573 & 1.000 & 0.013 & & & \\
\hline $\mathrm{SU}_{\mathrm{dry}}$ & $10-15$ & 0.574 & 0.170 & 0.005 & 0.573 & 0.937 & 1.000 & & & \\
\hline $\mathrm{SU}_{\mathrm{dry}}$ & $15-25$ & 0.748 & 0.106 & 0.065 & 0.310 & 0.818 & 0.005 & & & \\
\hline \multirow[t]{2}{*}{$\mathrm{SU}_{\mathrm{dry}}$} & $25-35$ & 0.228 & 0.054 & 0.520 & 0.126 & 0.240 & 0.005 & & & \\
\hline & & \multicolumn{3}{|c|}{9 months } & \multicolumn{3}{|c|}{12 months } & & & \\
\hline $\mathrm{SU}_{\text {moist }}$ & $0-5$ & 0.748 & 0.037 & 0.005 & 0.375 & 0.468 & 0.005 & & & \\
\hline $\mathrm{SU}_{\text {moist }}$ & $5-10$ & 0.627 & 0.010 & 0.077 & 0.016 & 0.810 & 0.005 & & & \\
\hline $\mathrm{SU}_{\text {moist }}$ & $10-15$ & 0.871 & 0.172 & 0.044 & 0.164 & 0.006 & 0.065 & & & \\
\hline $\mathrm{SU}_{\text {moist }}$ & $15-25$ & 0.378 & 0.394 & 0.002 & 0.126 & 0.937 & 0.005 & & & \\
\hline \multirow[t]{2}{*}{$\mathrm{SU}_{\text {moist }}$} & $25-35$ & 0.043 & 0.748 & 0.126 & 0.054 & 1.000 & 0.005 & & & \\
\hline & & \multicolumn{3}{|c|}{3 months } & \multicolumn{3}{|c|}{9 months } & \multicolumn{3}{|c|}{12 months } \\
\hline WI & $0-5$ & 1.000 & 0.005 & 0.005 & 0.019 & 0.002 & 0.005 & 0.008 & 0.006 & 0.005 \\
\hline WI & $5-10$ & 0.458 & 0.012 & 0.008 & 0.045 & 0.008 & 0.008 & 0.074 & 0.034 & 0.008 \\
\hline WI & $10-15$ & 0.029 & 0.012 & 0.002 & 0.744 & 1.000 & 0.002 & 0.005 & 0.192 & 0.002 \\
\hline WI & $15-25$ & 0.468 & 0.419 & 0.078 & 0.808 & 0.873 & 0.002 & 0.005 & 0.016 & 0.002 \\
\hline WI & $25-35$ & 0.565 & 0.035 & 0.305 & 0.194 & 0.010 & 0.018 & 0.002 & 0.036 & 0.001 \\
\hline
\end{tabular}

